Manuscript prepared for Atmos. Chem. Phys.

with version 3.2 of the $\mathrm{LT}_{\mathrm{E}} \mathrm{X}$ class copernicus.cls.

Date: 22 July 2011

\title{
Supplement to: A new multi-gas constrained model of trace gas non-homogeneous transport in firn: evaluation and behavior at eleven polar sites
}

\author{
E. Witrant ${ }^{1}$, P. Martinerie ${ }^{2}$, C. Hogan ${ }^{3}$, J. C. Laube ${ }^{3}$, K. Kawamura ${ }^{4}$, E. Capron ${ }^{5,6}$, S. A. Montzka ${ }^{7}$, E. J. \\ Dlugokencky $^{7}$, D. Etheridge ${ }^{8}$, T. Blunier ${ }^{9}$, and W. T. Sturges ${ }^{3}$ \\ ${ }^{1}$ Grenoble Image Parole Signal Automatique (GIPSA-lab), Université Joseph Fourier / CNRS, BP 46, 38 402 Saint Martin \\ d'Hères, France \\ ${ }^{2}$ Laboratoire de Glaciologie et Géophysique de l'Environnement (LGGE), CNRS / Université Joseph Fourier, BP 96,38402 \\ Saint Martin d'Hères, France \\ ${ }^{3}$ School of Environmental Sciences, University of East Anglia, Norwich NR4 7TJ, UK \\ ${ }^{4}$ National Institute of Polar Research, 1-9-10 Kaga, Itabashi-ku, Tokyo 173-8515, Japan \\ ${ }^{5}$ Laboratoire des Sciences du Climat et de L'Environnement, IPSL/CEA-CNRS-UVSQ, 91191 Gif-sur-Yvette, France \\ ${ }^{6}$ British Antarctic Survey, Natural Environment Research Council, High Cross, Madingley Road, Cambridge CB3 0ET, UK \\ ${ }^{7}$ NOAA Earth System Research Laboratory, Boulder, Colorado, USA \\ ${ }^{8}$ Commonwealth Scientific and Industrial Research Organisation, Marine and Atmospheric Research, PMB 1, Aspendale, \\ Vic. 3195, Australia \\ ${ }^{9}$ Centre for Ice and Climate, Niels Bohr Institute, University of Copenhagen, Juliane Maries vej 30, DK-2100 Copenhagen $\varnothing$, \\ Denmark
}

\section{Direct model of gas transport in firn}

The notations chosen for the main physical variables are presented in Table 1. The subscript $\alpha$ is generally used for trace gases while the superscripts $o$ or $c$ indicate the considered 5 quantity in the open or closed porosity network, respectively. The first and second partial derivatives with respect to space are indicated with $[\cdot]_{z}$ and $[\cdot]_{z z}$, respectively, and the one with respect to time as $[\cdot]_{t} . \nabla$ is the gradient operator in 3-D space.

\subsection{Model equivalencies}

The proposed transport model

$$
\left\{\begin{array}{l}
{\left[\rho_{\alpha}^{o} f\right]_{t}+\left[\rho_{\alpha}^{o} f\left(v+w_{a i r}\right)\right]_{z}+\rho_{\alpha}^{o} \tau} \\
\quad-\left[D_{\alpha}\left(\left[\rho_{\alpha}^{o}\right]_{z}-\rho_{\alpha}^{o} \frac{\left[\rho_{a i r}\right]_{z}}{\rho_{a i r}}+\mathcal{A}_{s s}\right)\right]_{z}=0 \\
\rho_{\alpha}^{o}(0, t)=\rho_{\alpha}^{a t m}(t) \\
\frac{R T}{M_{f}}\left[\rho_{\alpha}^{o}\left(z_{f}, t\right)\right]_{z}-\rho_{\alpha}^{o}\left(z_{f}, t\right)=0
\end{array}\right.
$$

is expressed in terms of mass density as it was established from mass conservation. This allows for a direct relationship with the transport terms definition. While keeping the density as the main variable can be useful for a robust algorithm ${ }^{25}$ implementation, it is interesting to change the state variable

Correspondence to: Emmanuel WITRANT

(emmanuel.witrant@gipsa-lab.grenoble-inp.fr)

\subsubsection{Equivalence with formulation in amount of gas}

Defining the gas quantity $q(z, t)=f(z) \times \rho_{\alpha}^{o}(z, t)$, (1) is equivalent to:

$$
\left\{\begin{array}{l}
q_{t}+\left[q\left(v+w_{\text {air }}\right)\right]_{z}+q \tau / f \\
\quad-\left[D_{\alpha}\left([q / f]_{z}-q / f \frac{\left[\rho_{a i r}\right]_{z}}{\rho_{a i r}}+\mathcal{A}_{s s}\right)\right]_{z}=0 \\
q(0, t)=f(0) \rho_{\alpha}^{a t m}(t) \\
\frac{R T}{M_{f}}\left[q\left(z_{f}, t\right) / f\left(z_{f}\right)\right]_{z}-q\left(z_{f}, t\right) / f\left(z_{f}\right)=0
\end{array}\right.
$$

The model proposed by Rommelaere et al. (1997) is obtained from equation (2) if $\mathcal{A}_{s s}=A_{s s, s i m}$ (the convective region was constructed by setting $q$ as constant in the upper part), $D_{\alpha}=f D$ (the diffusivity is directly defined as one in a porous media), $q\left(z_{f}, t\right)=0$ (no gas in contact with the atmosphere in the last layer) and adding a radioactive decay term (which was not considered here as it does not apply to the studied gases but could simply be introduced as a mass loss on $\rho_{\alpha}^{o}$ ). When this model was used in a first attempt to calculate a multi-gas constrained diffusivity, some problems appeared due to the convective region (lack of accuracy in the upper part) and to numerical oscillations (bottom boundary condition and terms containing the inverse of $f$, that goes to zero at the end of the close-off region). 
Table 1. Main physical variables

\begin{tabular}{|c|c|}
\hline Notation & Physical variable \\
\hline $\mathcal{A}_{s s}(z)$ & global steady-state Darcy transport term $\left(\mathrm{kg} . \mathrm{m}^{-4}\right)$ \\
\hline$A_{s s}(z)$ & local steady-state Darcy transport term $\left(\mathrm{kg} \cdot \mathrm{m}^{-4}\right)$ \\
\hline$a_{a c c u}$ & snow accumulation rate ( $m$ eq water $/ y r$ ) \\
\hline$c(z, t)$ & mass concentration $\left(\mathrm{kg} \cdot \mathrm{m}^{-3}\right)^{1}$ \\
\hline$D(z)$ & diffusivity $\left(\mathrm{m}^{2} \mathrm{yr}^{-2}\right)$ \\
\hline$D_{\alpha}(z)$ & effective diffusivity of gas $\alpha$ in firn $\left(\mathrm{m}^{2} \mathrm{yr}^{-2}\right)$ \\
\hline$D_{e f f}(z)$ & effective diffusivity of $\mathrm{CO}_{2}$ in firn $\left(\mathrm{m}^{2} \mathrm{yr}^{-2}\right)$ \\
\hline$D_{\alpha, g}$ & $\begin{array}{l}\text { molecular diffusion coefficient of gas } \alpha \text { in free air } \\
\left(\mathrm{m}^{2} \mathrm{yr}^{-2}\right)\end{array}$ \\
\hline$D_{\text {air }}$ & molecular $\mathrm{CO}_{2}$ diffusivity in free air $\left(\mathrm{m}^{2} \mathrm{yr}^{-2}\right)$ \\
\hline $\begin{array}{l}D_{e d d y}(z) \\
f(z)\end{array}$ & $\begin{array}{l}\text { eddy component in effective diffusivity }\left(\mathrm{m}^{2} \mathrm{yr}^{-2}\right) \\
\text { open porosity }\left(\mathrm{m}^{3} \mathrm{~m}^{-3}\right)\end{array}$ \\
\hline$g$ & gravitational acceleration $\left(9.81 \mathrm{~m} . \mathrm{s}^{-2}\right)$ \\
\hline$M$ & $\mathrm{~s}(\mathrm{~kg} / \mathrm{mol})$ \\
\hline$m(z)$ & measured mixing ratio $(\mathrm{mol} / \mathrm{mol})$ \\
\hline$N_{g}$ & number of trace gases \\
\hline$P(z)$ & pressure $(\mathrm{Pa})$ \\
\hline$r^{x \rightarrow y}(z)$ & $\begin{array}{l}\text { rate of fluid mass transfer from } x \text { to } y \\
\left(\mathrm{~kg} \cdot \mathrm{m}^{-3} \cdot \mathrm{yr}^{-1}\right)\end{array}$ \\
\hline$R$ & ideal gas constant $\left(8.314 \mathrm{~J} \cdot \mathrm{mol}^{-1} . \mathrm{K}^{-1}\right)$ \\
\hline$T$ & firn temperature $(\mathrm{K})$ \\
\hline$v(z)$ & firn sinking speed $(\mathrm{m} / \mathrm{yr})$ \\
\hline$w_{f}(z, t)$ & $\begin{array}{l}\text { relative fluid advection speed with respect to } v \\
(\mathrm{~m} / \mathrm{yr})\end{array}$ \\
\hline$z$ & depth location in the firn (m) \\
\hline$\Delta z$ & depth increment between model layers ( $\mathrm{m}$ ) \\
\hline$\epsilon(z)$ & total $\mathrm{p}$ \\
\hline$\kappa(z)$ & perme \\
\hline$\lambda$ & ive decay rate \\
\hline$\mu$ & ity $\left(\mathrm{kg} \cdot \mathrm{m}^{-1} \mathrm{yr}^{-1}\right)$ \\
\hline$\nu(z)$ & the firn tortuosity \\
\hline$\chi_{x}$ & $\begin{array}{l}\text { mole fraction of gas } x \text { (trace gas or air) in the gas } \\
\text { mixture }\end{array}$ \\
\hline$\phi(w, t)$ & vector $(\mathrm{m} / \mathrm{yr})$ \\
\hline$\rho_{\text {firn }}(z)$ & lepth $\left(\mathrm{kg} \cdot \mathrm{m}^{-3}\right)$ \\
\hline$\rho_{\text {ice }}(z)$ & ice density $\left(\mathrm{kg} \cdot \mathrm{m}^{-3}\right)$ \\
\hline$\rho_{\text {air } / \alpha}^{o}(z, t)$ & air/trace gas density in open pores $\left(\mathrm{kg} \cdot \mathrm{m}^{-3}\right)$ \\
\hline$\rho_{\text {air } / \alpha}^{c}(z, t)$ & air/trace gas density in closed pores $\left(\mathrm{kg} \cdot \mathrm{m}^{-3}\right)$ \\
\hline$\varrho_{\alpha}$ & $\begin{array}{l}\text { relative diffusivity of trace gas } \alpha \text { with respect to } \\
D_{\text {air }}\end{array}$ \\
\hline$\sigma(z)$ & uncertainty on measured mixing ratios $(\mathrm{mol} / \mathrm{mol})$ \\
\hline$\tau(z)$ & $\begin{array}{l}\text { rate of gas volume exchange between open and } \\
\text { closed networks }\left(\mathrm{yr}^{-1}\right)\end{array}$ \\
\hline$\omega_{\alpha}$ & specific weight of gas $\alpha$ in the cost function \\
\hline
\end{tabular}

\subsubsection{Equivalence with a formulation in gas concentra- tions, using a Lagrangian frame}

The transport model (1) can be expressed in terms of gas concentration $c(z, t)=\rho_{\alpha}^{o}(z, t) / \rho_{\text {air }}(z)$ by noticing that:

$$
\rho_{\alpha}^{o}=c \rho_{a i r}, \quad\left[\rho_{\alpha}^{o}\right]_{z}=\rho_{a i r}[c]_{z}+\left[\rho_{a i r}\right]_{z} c
$$

and (air transport and trapping equilibrium):

$$
\left[\rho_{\text {air }} f\left(v+w_{\text {air }}\right)\right]_{z}+\rho_{\text {air }} \tau=0
$$

The gas dynamics is then expressed in terms of concentration as:

$$
\frac{\partial c}{\partial t}+\left(v+w_{a i r}\right)[c]_{z}=\left(\frac{f_{z}}{f}+\frac{\left[\rho_{a i r}\right]_{z}}{\rho_{a i r}}\right) \Phi+[\Phi]_{z}
$$

with the mixing ratio flux $\Phi(z, t)=D\left([c]_{z}+\mathcal{A}_{s s} / \rho_{\text {air }}\right)$ and $D=D_{\alpha} / f$.

Our model is set in an Eulerian frame (fixed with respect to the surface) and can be expressed in a Lagrangian coordinate (moving with particles that have a speed $v+w_{a i r}$ in the Eulerian frame) using the relationship:

$$
\frac{d c}{d t}=\frac{\partial c}{\partial t}+\left(v+w_{a i r}\right)[c]_{z}
$$

where $d / d t$ denotes the Lagrangian derivative. The dynamics (3) is then equivalent to:

$$
\frac{d c}{d t}=\left(\frac{f_{z}}{f}+\frac{\left[\rho_{a i r}\right]_{z}}{\rho_{a i r}}\right) \Phi+[\Phi]_{z}
$$

and the air transport model (determined by firn sinking and air trapping) defines the absolute position (Eulerian frame) of the relative coordinates, which is necessary to relate the modeled concentrations to the firn measurements. Comparing this expression with the model proposed by Trudinger et al. (1997), the equivalence is established (neglecting the radioactive decay) if $\left[\rho_{\text {air }}\right]_{z} / \rho_{\text {air }}=M_{\text {air }} g / R T$ (hydrostatic air distribution) and $\mathcal{A}_{s s}=A_{s s, s i m}$. The main advantage of the Lagrangian framework is that it allows us to track surface alterations of the flux within the firn. Indeed, the snow melting process is thus modeled by Trudinger et al. (1997) as the sinking of a layer with reduced diffusivity. Such a phenomenon could be mapped in the Eulerian framework by defining a time-varying diffusivity, parameterized in terms of the firn sinking speed. However, it involves in both cases the use of finer numerical schemes (and hence larger simulation times) that are not compatible with the proposed multi-gas optimization goal.

\subsubsection{Equivalence with an isotopic ratio formulation}

Isotopic ratios are geochemical variables of particular interest for the study of inert gases. When an isotopic ratio is mostly constant in the atmosphere, its values in firn can be 
used, for example, to compare the timing of greenhouse gas changes versus climate (Severinghaus et al., 1998). The behavior of an isotopologue 1 with respect to isotopologue 2 is typically expressed with the geochemical $\delta$ notation:

$$
\delta=\left(\frac{\chi_{1,2}}{R_{s t d}} \frac{M_{2}}{M_{1}}-1\right) \times 10^{3}=\left(\frac{\rho_{1} / \rho_{2}}{R_{s t d}} \frac{M_{2}}{M_{1}}-1\right) \times 10^{3}
$$

where $\delta$ is expressed in $\%, \chi_{1,2}$ is the mass ratio of gas 1 55 the standard molar ratio for the gases considered (constant scalar variable), $\rho_{1,2}$ are the concentrations in air and the ratio of molar masses $M_{2} / M_{1} 85$ is introduced to express the mass ratio in terms of a molar ratio.

If $\rho_{1}$ and $\rho_{2}$ are both considered to vary with time and depth, the computation of $\delta$ implies to solve the transport equations (1) for both isotopes in air in parallel and then ob- 9 tain their ratio. If 2 is considered as a dominant gas that has a constant concentration with respect to time and is transported with air, a compact expression can be obtained for $\delta$. First, setting $\left[\rho_{2}\right]_{t}=0$ implies that (3) writes equivalently as (considering the transport in gas 2 instead of air):

$f \rho_{2}\left[\chi_{1,2}\right]_{t}+f \rho_{2}\left(v+w_{2}\right)\left[\chi_{1,2}\right]_{z}=\left[f D_{1,2}\left(\left[\chi_{1,2}\right]_{z} \rho_{2}+\mathcal{A}_{s s}\right)\right]_{z}$

60 where $D_{1,2}$ is the diffusivity of gas 1 in gas 2 . Then, expressing $\chi_{1,2}$ and its partial derivatives in terms of $\delta$ and $\rho_{2}$ provides the dynamics:

$$
\begin{aligned}
f \frac{\partial \delta}{\partial t} & +f\left(v+w_{a i r}\right)[\delta]_{z} \\
& =\frac{1}{\rho_{2}}\left[\rho_{2} f D_{1,2}\left([\delta]_{z}+\frac{M_{2} / M_{1} \times 10^{3}}{R_{s t d} \rho_{2}} \mathcal{A}_{s s}\right)\right]_{z}
\end{aligned}
$$

This transport model can be compared with the one proposed by Severinghaus et al. (2010). Both models are equivalent if: (1) the depth variations in $\rho_{2}$ are neglected $\left(\left[\rho_{2}\right]_{z}=0\right)$ to simplify the flux derivative, (2) an eddy diffusion term is added specifically to the flux associated with Fick's law (it does not affect $\mathcal{A}_{s s}$ ), (3) the steady-state equilibrium is set with (considering the depth-variations of the temperature):

$$
\mathcal{A}_{s s}=\frac{R_{s t d} \rho_{2}}{M_{2} / M_{1} \times 10^{3}}\left(\frac{\left(M_{2}-M_{1}\right) g}{R T}(\delta+1)+\Omega[T]_{z}\right)
$$

where $\Omega$ is the thermal diffusion sensitivity. The first term on ${ }^{115}$ the right side of the previous equation corresponds to $A_{s s, s i m}$ computed on $\left(M_{2}-M_{1}\right)$ while the second term denotes an external force applied on the fluid by the temperature gradient. The fact that $A_{s s, s i m}$ contains $M_{2}$ (which comes from $\left.{ }_{70}\left[\rho_{2}\right]_{z} / \rho_{2}=M_{2} g / R T\right)$ reflects the impact of the hydrostatic pressure variations of 2 on the transport model (hence the hypothesis $\left[\rho_{2}\right]_{z}=0$ is only partially used, to simplify the flux expression). Such analogy may be useful to associate the proposed model with a module of heat transport in firn and investigate the impact of temperature gradients on the transport of gases.

\subsection{Discretization of the transport equation}

\subsubsection{Background on the discretization of PDEs}

The proposed trace gas transport model belongs to the general class of models described by:

$$
\begin{aligned}
& {[q]_{t}=\mathcal{D}[q]_{z z}+\mathcal{C}[q]_{z}+\mathcal{S} q} \\
& q(0, t)=q_{0}(t), \quad k_{1}[q]_{z}\left(z_{f}, t\right)+k_{2} q\left(z_{f}, t\right)=0
\end{aligned}
$$

where $q(z, t)$ is a generic transported variable, $\mathcal{S}(z)$ a sink term and $k_{1}$ and $k_{2}$ ensure that the net flux at $z_{f}$ (location of the end boundary condition, e.g. bottom of the firn) is zero. The transport coefficients $\mathcal{D}(z)$ and $\mathcal{C}(z)$, associated with the second and first spacial derivatives, are referred to as diffusion and convection, respectively. This distinction, instead of the physical diffusive and advective transport used previously, is motivated by the specificities of the associated mathematical aspects and numerical schemes.

The discretized model is set by introducing $Q^{k}=$ $\left[Q_{1}^{k} \ldots Q_{i}^{k} \ldots Q_{N}^{k}\right]^{T} \in \mathbb{R}^{N \times 1}$ as the vector of discretized $q(z, t)$ at the space locations $z_{i}$ and the time instant $t_{k}$. The 95 resulting variation law for depth $i$ (considering an implicit time discretization scheme, for example) is:

$$
\begin{aligned}
Q_{i}^{k+1}=Q_{i}^{k} & +t_{s}\left[\mathcal{D}_{i} D\left(Q_{i-1}, Q_{i}, Q_{i+1}\right)^{k+1}\right. \\
& \left.+C\left(Q_{i-1}, Q_{i}, Q_{i+1}, \mathcal{C}_{i}\right)^{k+1}+\mathcal{S}_{i} Q_{i}^{k+1}\right]
\end{aligned}
$$

where $t_{s}$ is the sampling time and $D(\cdot)$ and $C(\cdot)$ are the discretization operators for diffusion and convection, respectively.

The space-discretization can be achieved, for example, with a central difference scheme for $D$ and a Lax-Wendroff (LW) scheme for $C$ (the model thus remains stable for $\mathcal{D}(z)=0$ provided that the Courant-Friedrichs-Lewy condition, denoted as CFL in the sequel, is satisfied). The choice of a LW scheme is also motivated by the improved accuracy for convection modeling (the numerical diffusion typically associated with a central or first order upwind scheme is thus avoided). Further details on the stability of the numerical schemes may be found in PDE or computational fluid dynamics textbooks, such as (Mattheij et al., 2005) or (Hirsch, 2007). According to this choice:

$$
\begin{aligned}
& D\left(Q_{i-1}, Q_{i}, Q_{i+1}\right)^{k+1}=\left(Q_{i-1}^{k+1}-2 Q_{i}^{k+1}+Q_{i+1}^{k+1}\right) / \Delta z^{2} \\
& C\left(Q_{i-1}, Q_{i}, Q_{i+1}, \mathcal{C}_{i}\right)^{k+1}= \\
& \quad \frac{\alpha_{i}}{t_{s}}\left(\frac{\alpha_{i}-1}{2} Q_{i-1}^{k+1}-\alpha_{i} Q_{i}^{k+1}+\frac{\alpha_{i}+1}{2} Q_{i+1}^{k+1}\right)
\end{aligned}
$$

where $\Delta z$ is the spatial step and $\alpha_{i}=\mathcal{C}_{i} t_{s} / \Delta z$.

Considering the fact that the transport coefficients are assumed to be constant in time and introducing the timevarying boundary condition on $q(0, t)$ with the vector $Q_{0}^{k}=$ $\left[q_{0}^{k} 0 \ldots 0\right]^{T} \in \mathbb{R}^{N \times 1}$, the discretized model writes in the matrix form:

$$
\begin{aligned}
Q^{k+1} & =Q^{k}+t_{s}\left[\mathcal{A} Q^{k+1}+\mathcal{B} Q_{0}^{k+1}\right] \\
\Leftrightarrow Q^{k+1} & =\left(I / t_{s}-\mathcal{A}\right)^{-1}\left[I / t_{s} Q^{k}+\mathcal{B} Q_{0}^{k+1}\right]
\end{aligned}
$$


where $\mathcal{A}=\mathcal{A}_{D}+\mathcal{A}_{C S}$ and $\mathcal{B}=\mathcal{B}_{D}+\mathcal{B}_{C S} . \mathcal{A}_{D}, \mathcal{A}_{C S}$ are tri-diagonal matrices and $\mathcal{B}_{D}, \mathcal{B}_{C S}$ are vectors with entries:

$$
\begin{gathered}
\mathcal{A}_{D, 1}=\frac{\mathcal{D}_{1}}{\Delta z^{2}}[0,-2,1], \quad \mathcal{A}_{D, i}=\frac{\mathcal{D}_{i}}{\Delta z^{2}}[1,-2,1], \\
\mathcal{A}_{D, N}=\frac{\mathcal{D}_{N}}{\Delta z^{2}}[1,-1,0], \\
\mathcal{A}_{C S, 1}=\frac{\alpha_{1}}{t_{s}}\left[0,-\alpha_{1}, \frac{\alpha_{1}+1}{2}\right]+\mathcal{S}_{1}, \\
\mathcal{A}_{C S, i}=\frac{\alpha_{i}}{t_{s}}\left[\frac{\alpha_{i}-1}{2},-\alpha_{i}, \frac{\alpha_{i}+1}{2}\right]+\mathcal{S}_{i}, \\
\mathcal{A}_{C S, N}=\frac{\alpha_{N}}{t_{s}}\left[\frac{\alpha_{N}-1}{2}, \frac{-\alpha_{N}+1}{2}, 0\right]+\mathcal{S}_{N}, \\
\mathcal{B}_{D, 1}=\frac{\mathcal{D}_{1}}{\Delta z^{2}}[1], \quad \mathcal{B}_{C S, 1}=\frac{\alpha_{1}}{t_{s}}\left[\frac{\alpha_{1}-1}{2}\right]
\end{gathered}
$$

where $[\cdot, \cdot, \cdot]$ is a line vector with three entries, centered at the $i$ index (used as both line and column indexes)

This space-discretization can also be used in an explicit time-discretization scheme for specific purposes, in which ${ }^{18}$ case:

$$
\begin{aligned}
Q^{k+1} & =Q^{k}+t_{s}\left[\mathcal{A} Q^{k}+\mathcal{B} Q_{0}^{k}\right] \\
\Leftrightarrow Q^{k+1} & =t_{s}\left[\left(I / t_{s}+\mathcal{A}\right) Q^{k}+\mathcal{B}_{D} Q_{0}^{k}\right]
\end{aligned}
$$

Hybrid explicit/implicit schemes (such as Crank-Nicolson if the weight of each is equivalent) may also be devised.

Note that for gases with constant atmospheric concentration $Q_{0}^{k}=Q_{0}$ is constant (no time-varying input in the model) and the concentration profile is directly obtained ( $\mathrm{a}^{195}$ time loop is unnecessary) as $Q=\mathcal{A}^{-1} \mathcal{B} Q_{0}$. This relationship is also used in the numerical model as an estimate of the initial condition, as it depicts the gas equilibrium in the firn if the atmospheric concentration remained constant for a "sufficiently long" period of time.

\subsubsection{Impact of space discretization}

The discretization schemes discussed in the previous section are illustrated on NEEM Greenland site (EU hole) with a 205 multi-gases diffusivity calculated with 395 depth levels. All simulations were performed with the same diffusivity profile, obtained from the inverse diffusivity model set with a LW scheme sampled with $N=395$ depths and atmospheric scenarii provided every month.

The impacts of the convection term discretization scheme and the number of discretization depths are presented in Figure 1, where LW, central and first-order upwind (FOU) discretizations are compared for three numbers of depths $N$. Concerning the effect of $N$, it appears that large differences ${ }_{215}$ occur between $N=100$ and $N=200$ but $N=200$ provides a good approximation of the full resolution $(N=395)$. Concerning the convection term discretization scheme, central difference tends to be more sensitive to the space discretization. Only slight differences can be observed for $N=395220$ except for the gases with constant atmospheric concentrations, for which the central scheme induces an important mismatch at the upper BC (removed from the figure). The improvements of the central and FOU schemes on some gases (i.e. $\mathrm{SF}_{6}$ and $\mathrm{CH}_{3} \mathrm{CCl}_{3}$ ) are balanced by an increased error on some others (i.e. CFCs and HFC-134a). This is directly related to the fact that the inverse diffusivity model 75 involves a balance amongst all the gases and all the measurement depths. A different discretization scheme in the inverse diffusivity model would imply a different diffusivity profile, which inherently accounts for the numerical properties of the model.

Similar conclusions can be obtained on Antarctica sites (for example at Dome C, presented on Figure 2), where discrepancies can be observed with a central scheme, while FOU tends to increase the convective transport.

\subsubsection{Impact of time discretization}

The effect of time-discretization is investigated on Figure 3 where explicit, equally balanced explicit/implicit (Crank Nicholson, denoted as $\mathrm{CN}$ ) and implicit schemes are compared for different sampling times $t_{s}$. The initial atmospheric scenarii being provided with $t_{s}=1$ month, linear interpolation is used for a finer time resolution. The convection space discretization is achieved with a LW scheme. Concerning the implicit or explicit/implicit schemes, it appears that choosing $t_{s}$ larger than a week tends to smooth out the transients due to seasonal variations (observed in the convective region for $\mathrm{CO}_{2}$ and $\mathrm{CH}_{4}$, and the peaks at $65-70 \mathrm{~m}$ for $\mathrm{CH}_{3} \mathrm{CCl}_{3}$ and ${ }^{14} \mathrm{CO}_{2}$ ). The explicit scheme necessitates a much smaller $t_{s}$ and to keep $t_{s} / \Delta z$ below a specific constant (approximation of the CFL condition), hence significantly increasing the direct model simulation time, as reported in Table 2. Explicit discretization experiences the same sensitivity with respect to $N$ as implicit discretization and an implicit scheme with $t_{s}=1$ week provides the same results as an explicit scheme with $t_{s}=30$ minutes. These results imply that an implicit or CN scheme with $t_{s}=1$ week is the most suitable for the inverse diffusivity model at Greenland sites, as it provides a reasonable trade-off between accuracy and simulation time. Running this time-discretization test on Antarctica sites (not presented here) leads to the same conclusions. Finally, generating the Green's function and running the inverse scenario model for both implicit and $\mathrm{CN}$ schemes has shown that $\mathrm{CN}$ may induce numerical instabilities for the atmospheric history reconstruction. Implicit time discretization is thus retained as the final choice.

Overall, using appropriate depth and time steps, the sensitivity of our model to the tested dicretization schemes is lower than its sensitivity to the relative weight factors of the different gases used for diffusivity minimization (see next section). Similar differences in discretization schemes are unlikely to explain the differences between firn models used in the inter-comparison study of Buizert et al. (2011). 

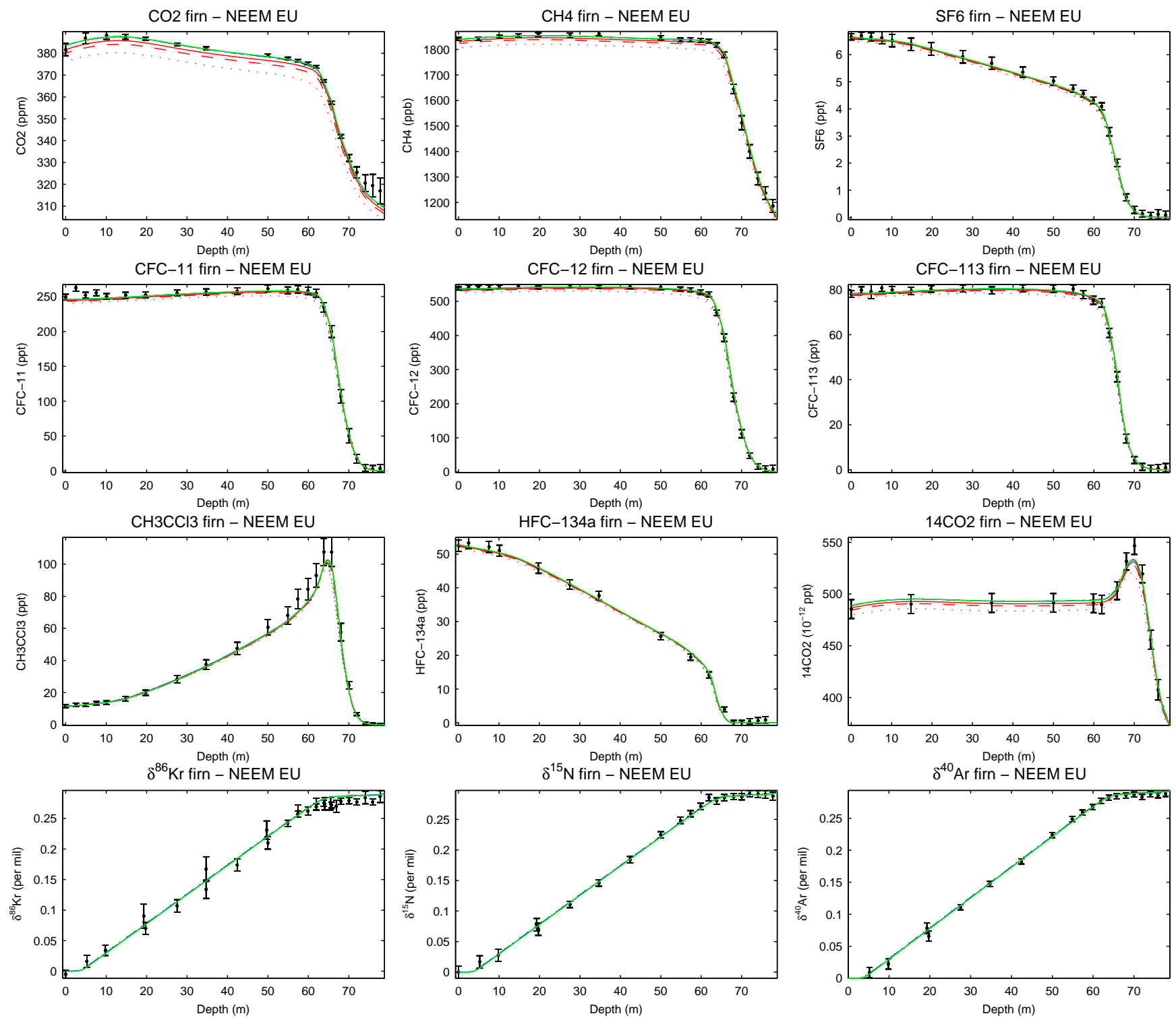

Fig. 1. Impact of the convection term discretization on the trace gases concentration at NEEM (EU hole) for 100 (' ...'), 200 ('- - -') and 395 ('-') depth levels ( $\Delta z \approx 0.8,0.4$ and $0.2 \mathrm{~m}$, respectively): Lax-Wendroff (blue, reference), central (red) and first order upwind (green).

\section{Inverse diffusivity model}

\subsection{Cost function normalization}

The impact of cost function normalization at NEEM $\left(\mathrm{EU}^{23}\right.$ hole) is illustrated by Figure 4, where the reference approach (based on measurements and scenario uncertainties) is compared with normalization approaches based on surface, average and maximum values of the concentrations in firn. The normalization by surface values gives more relative weight (values higher than one) to data points with concentrations higher than the surface value. It thus fits better gases for which the concentration is increasing with depth $\left(\mathrm{CH}_{3} \mathrm{CCl}_{3}\right.$ and ${ }^{14} \mathrm{CO}_{2}$ ), thus providing a better fit of their peaks in deep firn, but deteriorates other gases (such as $\mathrm{SF}_{6}$, HFC-134a and CFCs). The normalization by mean concentration emphasizes the gases with concentrations that do not cancel at the bottom of the firn $\left(\mathrm{CO}_{2}\right.$ and $\left.\mathrm{CH}_{4}\right)$. Normalizing with the maximum value gives the least weight to gases with a peak $\left(\mathrm{CH}_{3} \mathrm{CCl}_{3}\right.$ and $\left.{ }^{14} \mathrm{CO}_{2}\right)$ and is the closest to the reference case. 

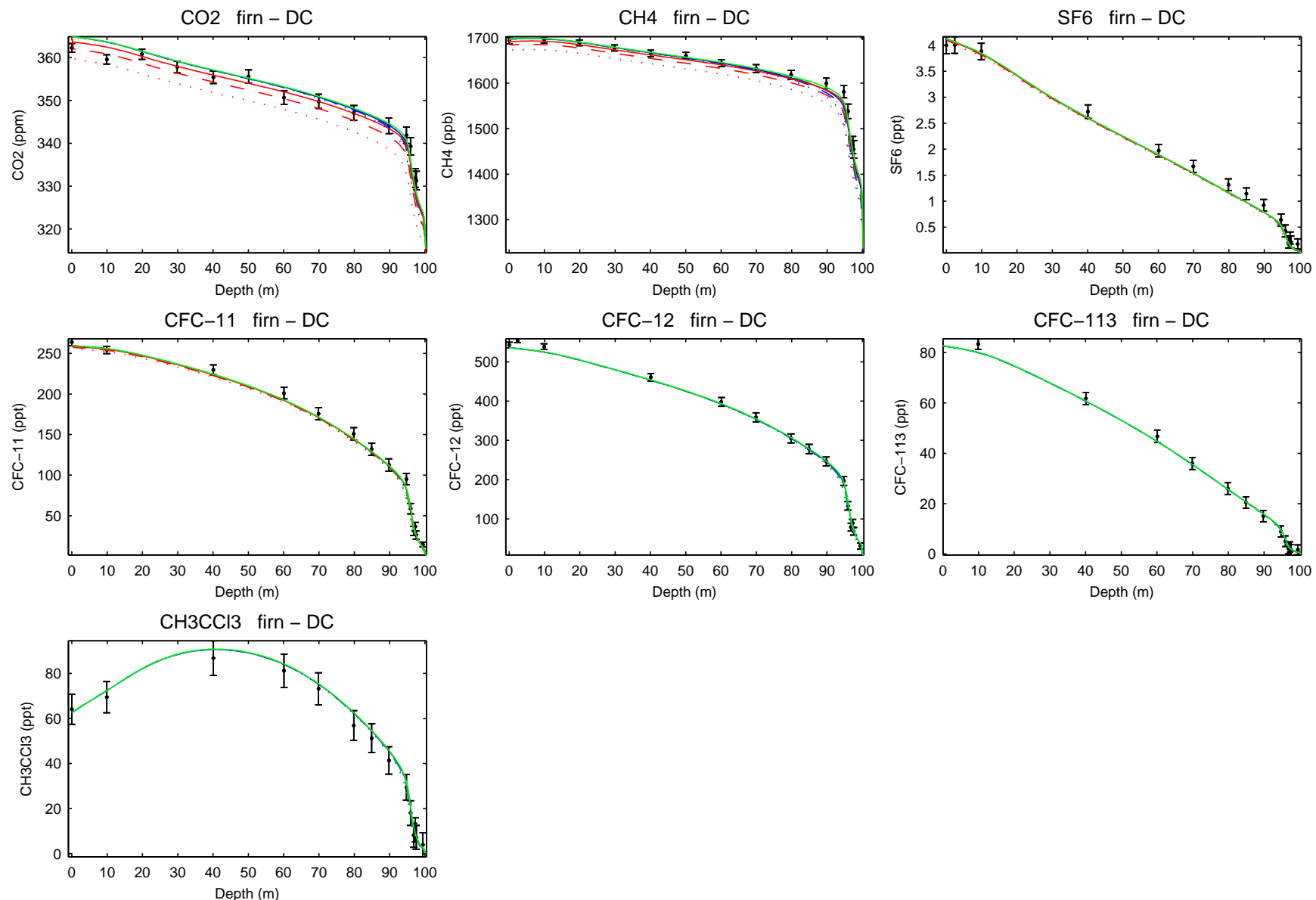

Fig. 2. Impact of the convection term discretization on the trace gases concentration at Dome $\mathrm{C}$ for $N=100$ (' $\cdots$ '), 200 ('- - -') and 502 ('-') depth levels ( $\Delta z \approx 1,0.5$ and $0.2 \mathrm{~m}$ ): Lax-Wendroff (blue, reference), central (red) and first order upwind (green).

\subsection{Single versus multiple gases at NEEM US}

Table 2. Averaged simulation time per gas associated with the proposed time-discretization schemes for NEEM EU (1800 to 2008, full close-off depth at $78.8 \mathrm{~m}, 12$ gases, left) and South Pole 1995 (1500 to 1995 , full close-off depth at $123 \mathrm{~m}$ ), obtained on a $P C$ laptop equipped with the processor i5 $540 \mathrm{~m}(2.53 \mathrm{Ghz}, 3 \mathrm{Mo})$ :

\begin{tabular}{lccr}
\hline Method & $t_{s}$ & $\Delta z^{a}$ & Simulation time $^{a}$ \\
\hline Implicit & 1 day & $0.2 \mathrm{~m}$ & $4.02 / 22.25 \mathrm{~s}$ \\
Implicit & 1 week & $0.2 \mathrm{~m}$ & $0.63 / 3.91 \mathrm{~s}$ \\
Implicit & 1 month & $0.2 \mathrm{~m}$ & $0.26 / 1.48 \mathrm{~s}$ \\
Explicit & $15 \mathrm{~min}$ & $0.2 \mathrm{~m}$ & $5.09 / 29.45 \mathrm{~min}$ \\
Explicit & $30 \mathrm{~min}$ & $0.4 / 0.61 \mathrm{~m}$ & $24.39 \mathrm{~s} / 1.34 \mathrm{~min}$ \\
Explicit $_{\text {Imp-explicit }}{ }^{b}$ & $1 \mathrm{~h}$ & $0.8 / 1.23 \mathrm{~m}$ & $7.19 \mathrm{~s} / 12.13 \mathrm{~s}$ \\
Imp-explicit $^{b}$ & 1 month & $0.2 \mathrm{~m}$ & $0.63 \mathrm{~s} / 3.77 \mathrm{~s}$ \\
\hline
\end{tabular}

${ }^{a}:$ NEEM EU / South Pole; ${ }^{b}$ : Crank-Nicholson.
Figures 5 and 6 are the NEEM-US equivalent of the NEEMEU results presented in Section 3.5 of the article. Only three reference gas datasets are available for the NEEM-US drill hole whereas nine were measured for the NEEM-EU drill hole. Figures 5 and 6 illustrate the fact that using two reference gases already strongly improves the robustness of the calculated diffusivity with respect to using only one reference gas.

\subsection{Additional sensitivity tests for NEEM-EU}

The inverse model for diffusivity calculation requires an initial solution to start the minimization procedure. In order to evaluate the impact of this initial diffusivity distribution on our results, two different calculations were performed at each site:
- one using a rough parameterization of diffusivity versus open porosity;



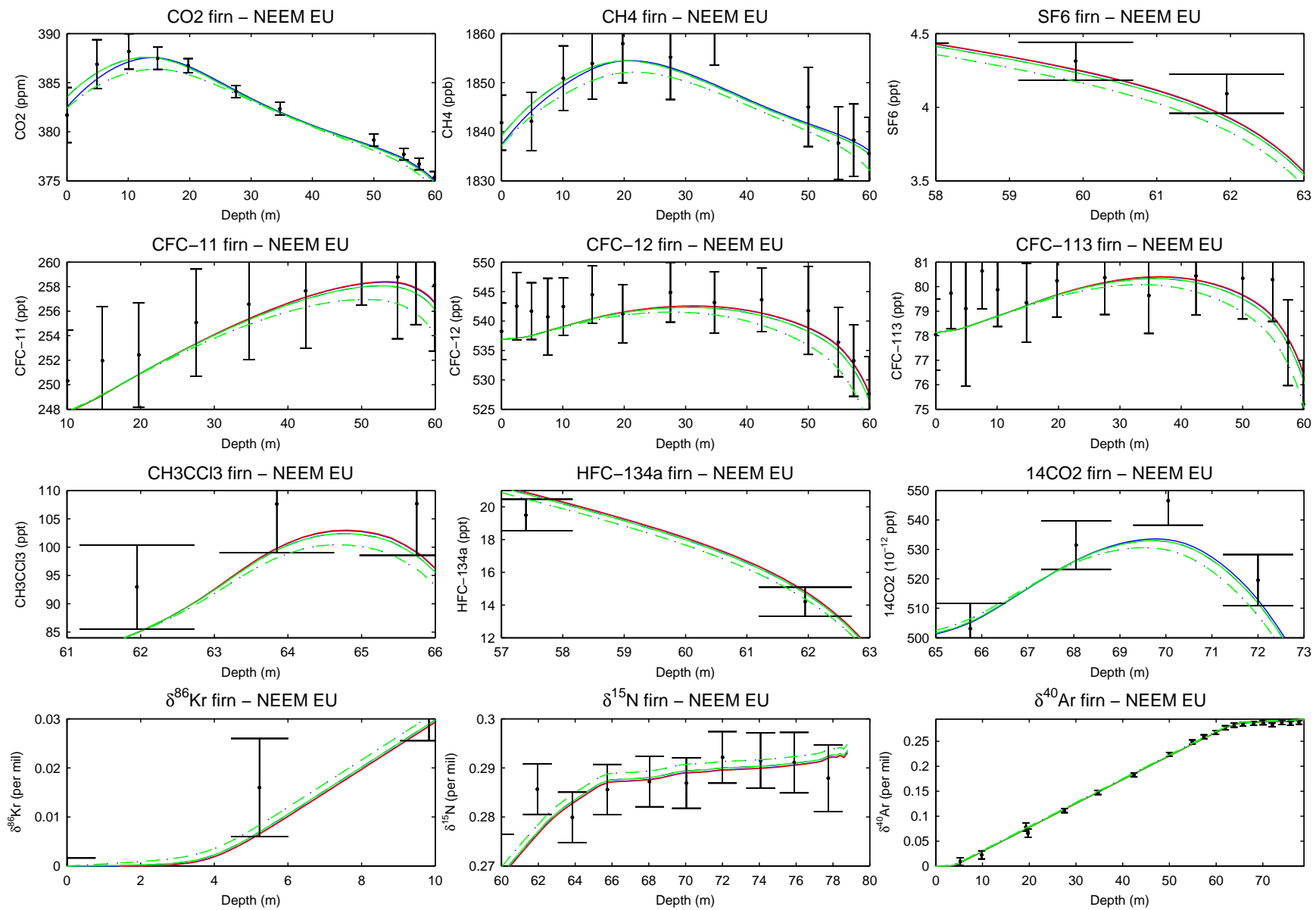

Fig. 3. Impact of the time discretization on the trace gases concentration at NEEM (EU hole, $\Delta z=0.2 \mathrm{~m}$ and a zoom on specific regions to highlight the differences): explicit with a sampling time $t_{s}=15$ minutes (red), implicit (blue) with $t_{s}=1$ day ('-'), 1 week (' --- ') and 1 month ('- - -'), and implicit-explicit (green) with $t_{s}=1$ week ('-') and 1 month ('---').

- one using a null diffusivity at all depths.

The simple parameterization used in the first case is the following: if $f>0.12$ and $D>1, D=(2.6 f-0.312) * D_{\text {air }}$, $D$ is the calculated initial diffusivity, $f$ the depthdependent open porosity of the firn and $D_{\text {air }}$ the $\mathrm{CO}_{2}$ diffusion coefficient in free air. Deeper in firn, defining $z_{1}$ as the 280 first depth at which $f<0.12$ or $D<1$, the following equation is used: $D=10^{10\left(z_{1}-z\right) /\left(z_{C O D}-z_{1}\right)}$, where $z_{C O D}$ is the full bubble close-off depth $(f=0)$. The second formulation allows for a faster decrease of the diffusivity with depth than the first. Figure 7 shows that the initial diffusivity profile 285 affects the final solution, but these differences are not large enough to induce a visible change on trace-gas concentrations in firn. As the minimization algorithm could converge to a local minimum (induced by the problem nonlinearities and non-uniqueness of the solution), the above two initial 290 conditions were used at all modeled sites (see Section 3). Two similar solutions are always obtained, suggesting that
Likely in relation with Arctic warming, the snow accumulation rate at NEEM has varied in the recent past: the mean accumulation rate over the last 200 years (used in our reference simulation) is $0.216 \mathrm{~m} / \mathrm{yr}$ ice equivalent, whereas the best estimate current day accumulation is $0.227 \mathrm{~m} / \mathrm{yr}$ ice equivalent (Buizert et al., 2011). Snow accumulation rate directly affects the firn sinking speed (or advection), thus it can potentially influence the model results, especially in the bubble close-off zone. Our results show that the accumulation rate only affects the ${ }^{14} \mathrm{CO}_{2}$ peak (see Figure 7), which occurs deep in the air trapping region (in comparison with the location of the $\mathrm{CH}_{3} \mathrm{CCl}_{3}$ peak, the air trapping is multiplied by 2.6 and the open porosity by 0.8 ). This illustrates a limitation induced by the stationary hypothesis made on the firn sinking (induced by a constant accumulation rate) and the potential sensitivity of gases that have an important transient behavior in the close-off region. 

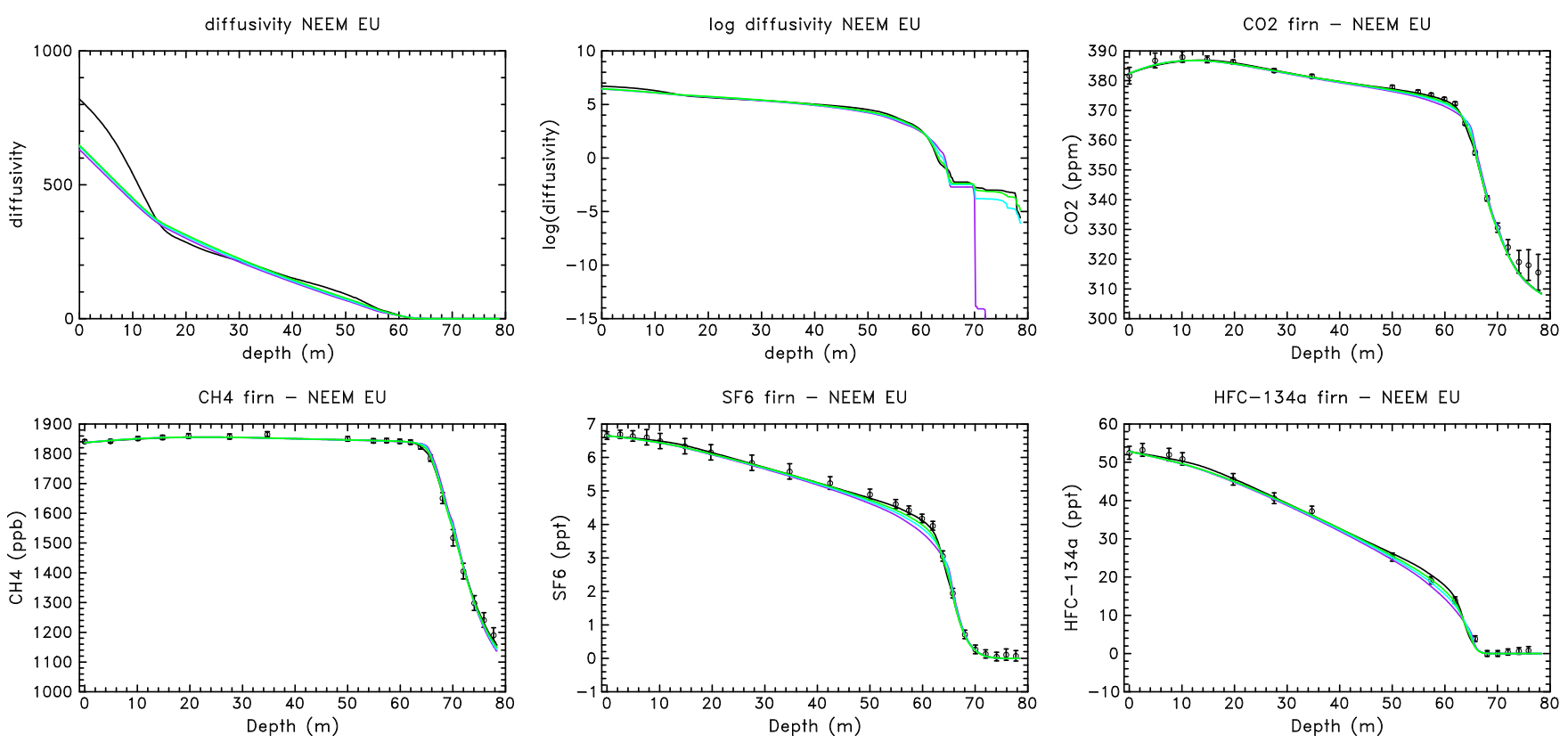

CH3CCI3 firn - NEEM EU
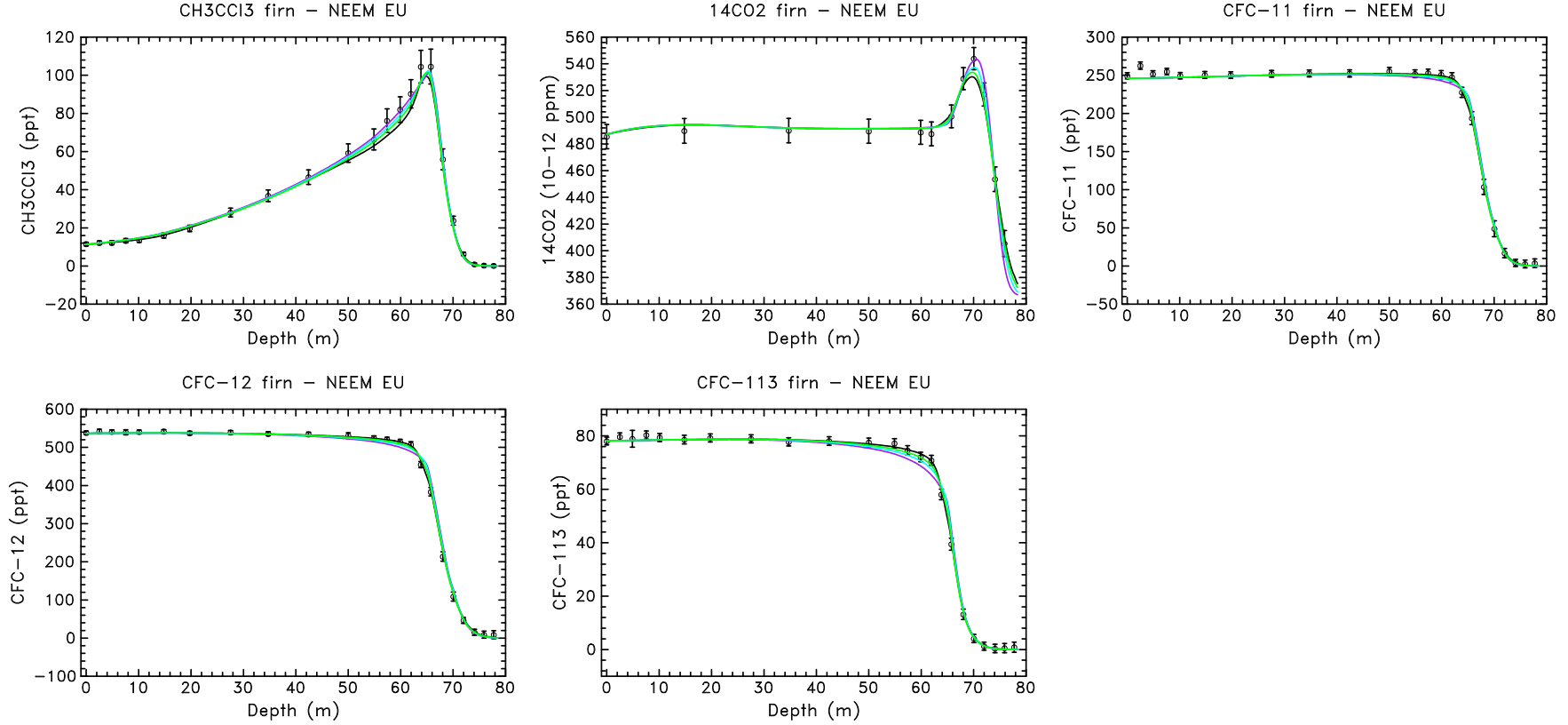

Fig. 4. NEEM diffusivity (in $\mathrm{m}^{2} /$ year) concentration profiles (EU hole) for different cost function normalization approaches: with uncertainties (black, reference solution), surface concentration (purple), average concentration (turquoise) and maximum value (green).

Another source of uncertainty on the model results in deep firn is the chosen parameterization of the closed porosity versus depth. Using the parameterization proposed by Severinghaus and Battle (2006) (modified to match the full close-off 305 depth of the reference simulation at NEEM) leads to a very similar result as modifying the accumulation rate: only the ${ }^{14} \mathrm{CO}_{2}$ peak height is affected, and it is similarly amplified. uses Goujon et al., 2003). In a last test, the full close-off depth was shifted deeper by one meter. Once again, only the ${ }^{14} \mathrm{CO}_{2}$ peak height is affected, and it changes less than when modifying the accumulation rate. Finally we should note that the fit of the reference gases dataset is not significantly affected by these tests (the RMSD changes by less than 0.01). induces no visible change from the reference solution (which 

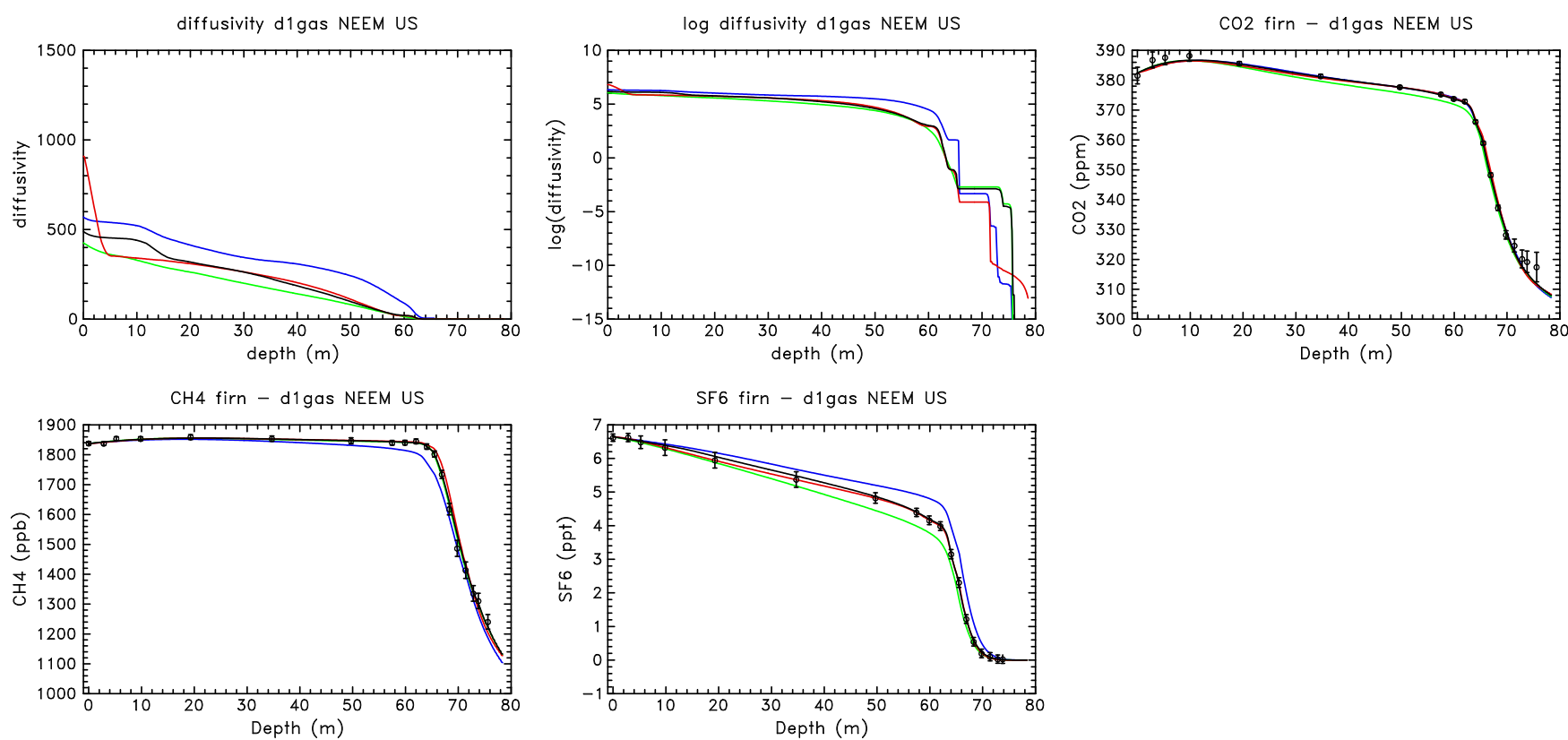

Fig. 5. Single gas inverse diffusivity model results for NEEM (US hole): each gas is used in turn to compute the diffusivity (in $\mathrm{m}^{2} / \mathrm{year}$ ). Results are shown for $\mathrm{CO}_{2}$ (blue), $\mathrm{CH}_{4}$ (green) and $\mathrm{SF}_{6}$ (red), and the 3 available gases (black, reference simulation).
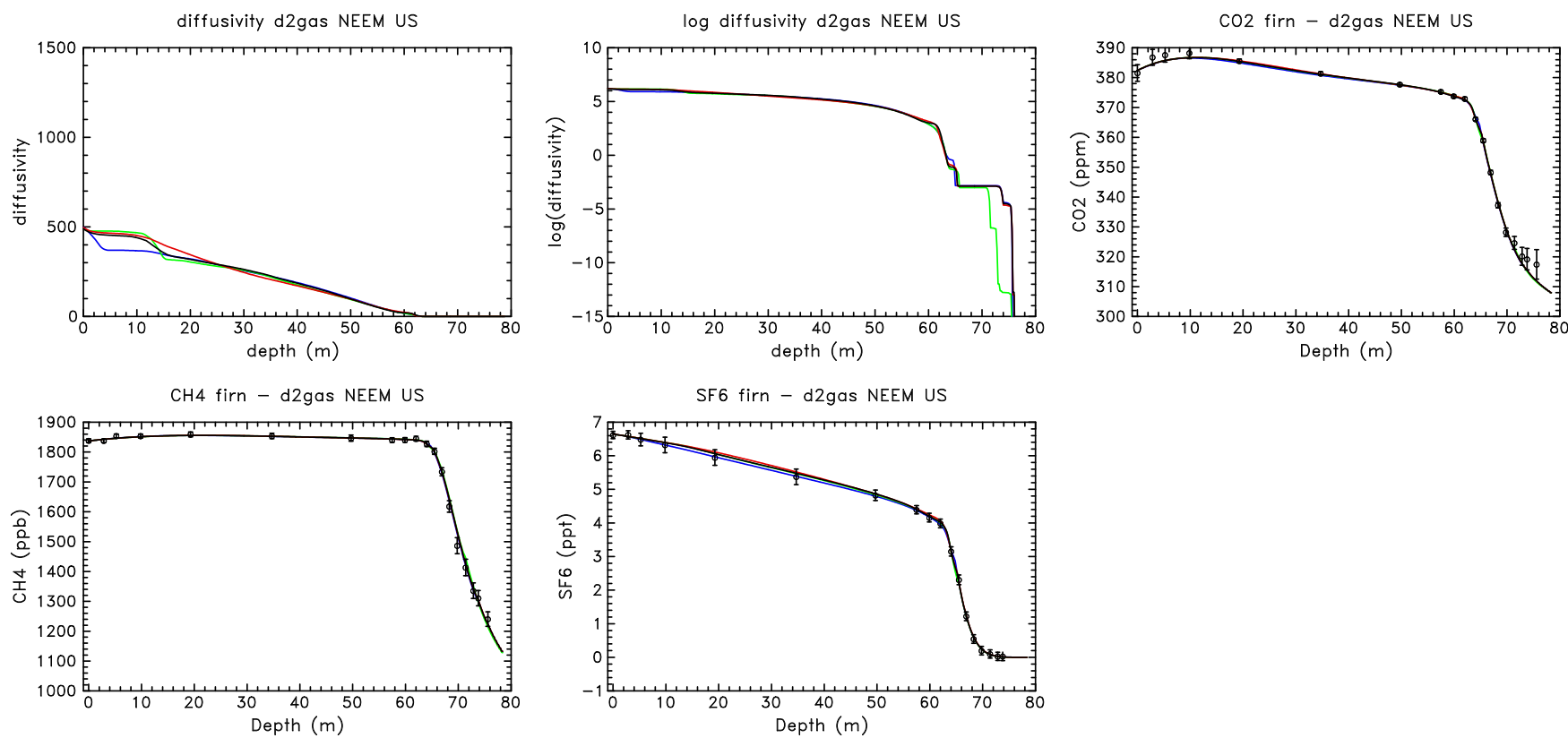

Fig. 6. Multiple gases inverse diffusivity model results for NEEM (US hole) using 2 reference gases: the dispersion of the diffusivities (in $\mathrm{m}^{2}$ /year) and concentrations is greatly reduced in comparison with the single gas diffusivity depicted in Figure 5. Results are shown without $\mathrm{CO}_{2}$ (blue), $\mathrm{CH}_{4}$ (green) and $\mathrm{SF}_{6}$ (red), and with the 3 available gases (black, reference simulation).

\section{Diffusivities at Arctic and Antarctic Sites other than} NEEM

\subsection{Datasets used to constrain the inverse model}

For each reference gas, the model uses an atmospheric time trend and concentrations in firn together with the associated uncertainties. The methodology used here is very similar to 15 the one described in detail by Buizert et al. (2011), thus this section will focus on the differences with respect to Buizert et al. (2011). 

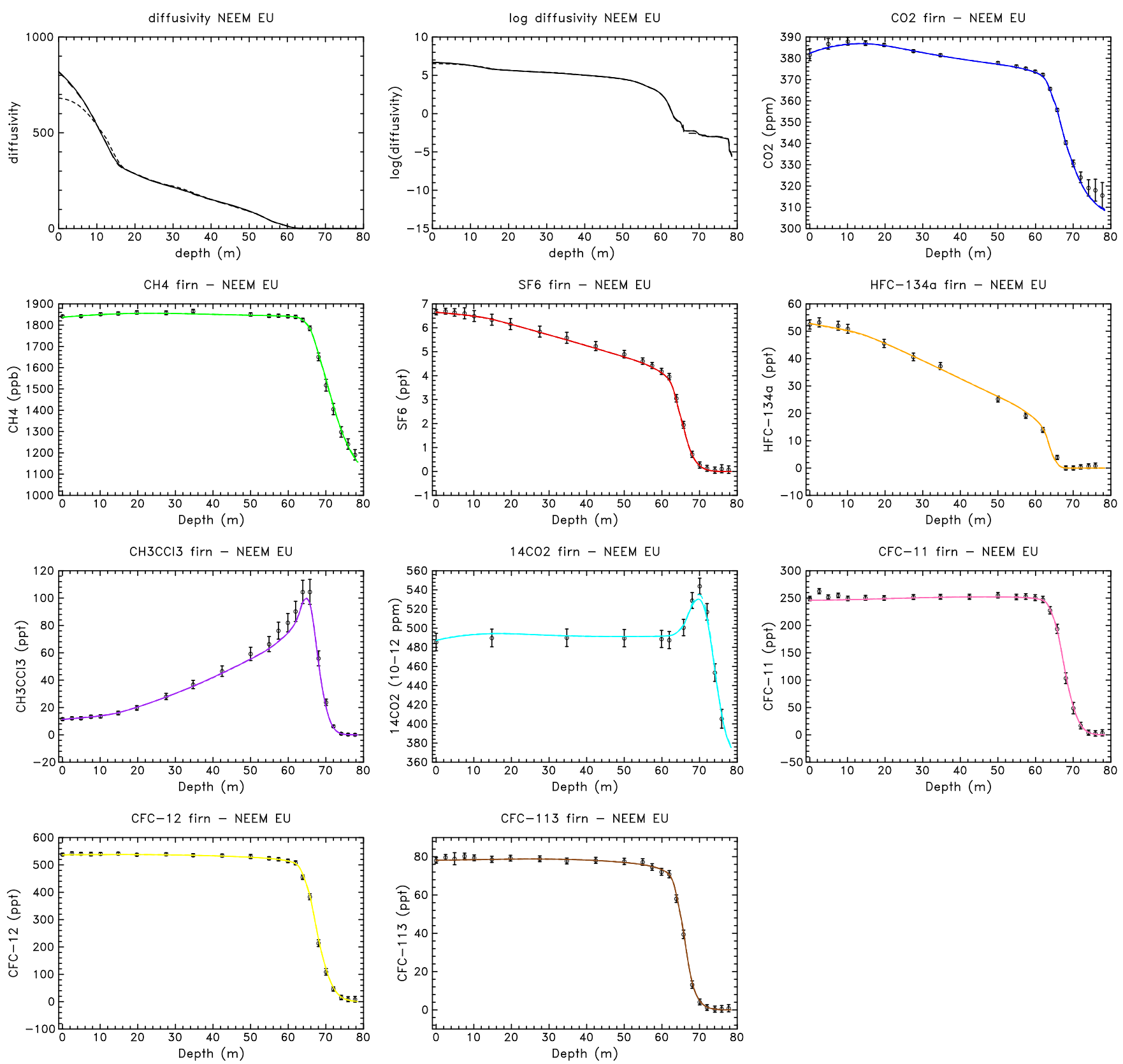

Fig. 7. Impacts of the initial solution and accumulation rate value at NEEM (EU hole) on the diffusivity profile (in $\mathrm{m}^{2} / \mathrm{year}$ ): reference solution (with a parameterized initial solution and an accumulation rate averaged over 200 years) ('-'), initial solution at zero for all depths ('- - ') and accumulation averaged over 20 years ('- - ').

The base atmospheric time trend scenarii used for Arctic sites are those described in Buizert et al. (2011), and the Antarctic scenarii are their analogs built using the consistent (same data sources) South Hemisphere datasets. We should 330 note that the short term variability (sub-monthly) of trace gas concentrations is smaller in the South Hemisphere than in the North Hemisphere as all species have dominant North Hemirecords were used when building North Hemisphere $\mathrm{CO}_{2}$ and ${ }_{335}$

$\mathrm{CH}_{4}$ scenarii, and the uncertainty on inter-hemispheric gradients does not apply to the South Hemisphere scenarii. Even with these reduced uncertainties, scenario errors are still the dominant error term in many cases for Antarctic sites. The calibration scales used to calculate best estimate trace gas concentrations have changed over time (see e.g. http: //www.esrl.noaa.gov/gmd/ccl/summary_table.html). Moreover, scale differences between atmospheric measurement networks need to be taken into account (see Buizert et al., 
2011, supplementary material). Our base atmospheric time trend scenarii were rescaled on a site by site basis to the 390 most appropriate scale, taking into account relevant uncertainties. For instance, $\mathrm{CH}_{3} \mathrm{CCl}_{3}$ uncertainties include unexplained variable differences between AGAGE and NOAA network measurements (Buizert et al., 2011). The figures below thus display the original datasets together with model 395 results using calibration scale-converted atmospheric time trend scenarii.

Uncertainties on firn data were estimated based on analytical precision and the consistency of duplicate measurements as in Buizert et al. (2011). When only few duplicates per 400 drill site were measured, but datasets obtained with the same methodology were available at several sites, the mean unthe consistent pool of datasets. Buizert et al. (2011) considered seven sources of error in the overall uncertainty: (1) Analytical precision, (2) Uncertainty in atmospheric reconstructions, (3) Contamination with modern air in the deepest firn samples, (4) Inter-laboratory and Unets, (5) Possibility of in-situ $\mathrm{CO}_{2}$ artifacts in deep firn, (6) Undersampling of seasonal cycle, (7) Unexplained EU-US borehole difference ( $\mathrm{SF}_{6}$ only). Errors (1), (2) and (6) were calculated with the same methodology. Error (4) could not be estimated in many cases as measurements were performed by a single laboratory. Error bars ${ }_{410}$ were enlarged when calibration-scale related issues were suspected, due to e.g. a constant offset in the upper firn between the direct model (scenario-based) results and firn data (see e.g. Martinerie et al., 2009). This reduces the weight of the suspect species with respect to other gases in the diffusivity calculation. Other error sources are site and species ${ }^{41}$ specific, we generally used data elimination rather than error bar enlarging in the presence of possibly contaminated data. Due to the fast diffusion of gases in the upper firn and age mixing in deep firn, trace gas profiles have to be somewhat smooth. Thus data points showing deviations from the expected smoothness are interpreted as outlier points. Eliminated data points are shown in grey on the following figures. In some cases (e.g. near the deepest sampling level), anoma- 420 lous concentrations are not straightforwardly detected. Specific tests related to that issue were performed at some sites. We should note that site by site adaptation by increase of error bars or data elimination reduces the risk of producing a biased solution due to the strong weight attributed to anoma- 425 lous data in the cost function. As a drawback, it also reduces the significance of comparing cost function values between sites. On the other hand, multi-gas diffusivity tuning can provide an improved way of evaluating the consistency of an overall dataset and detect outlier points. Further site by site 430 indications are provided in the relevant sections below.

\subsection{DE08}

DE08 is located near the top of the Antarctic Law Dome. The 435 measurements shown on Figure 8 were sampled at DE08-2 and performed at CSIRO (see Trudinger et al., 1997, and references therein). The deepest CFC-11 sample is inconsistent with the overall dataset and considered as an outlier (not used in diffusivity calculation). A more ambiguous situation occurs for the deepest $\mathrm{CO}_{2}$ sample for which the model/data difference falls just outside the error bar. As DE08 is a warm site, a deep firn $\mathrm{CO}_{2}$ anomaly similar to the one observed at NEEM (Buizert et al., 2011) or North GRIP (see Section 3.5) could be suspected. A sensitivity test was performed to compare diffusivities calculated with/without this data point. The effect is limited to the deepest firn, and $\mathrm{CH}_{4}$ (a fast diffusing species) is the most affected.

\subsection{Devon Island}

Devon Island, North GRIP, Berkner Island, Dronning Maud Land and Dome $\mathrm{C}$ firn air pumping operations were performed in the frame of two EC research programs, most datasets for these sites are available from the BADC database (FIRETRACC, 2007; CRYOSTAT, 2007). In this study, we privileged LGGE data for $\mathrm{CO}_{2}$ and $\mathrm{CH}_{4}$, and UEA halocarbon data to maximize the consistency of our diffusivities in the perspective of multi-site atmospheric time-trend reconstructions.

Multi-gas constrained diffusivity (Fig. 9) brings a remarkable improvement to the fit of the Devon Island dataset with respect to single-gas diffusivity (Martinerie et al., 2009). Only the multi-gas diffusivity follows the unusual wiggles in the trace gas depth-concentration profiles, which are likely due to the presence of about 150 refrozen melt layers in the Devon Island firn.

\subsection{Summit}

Reference gas measurements for Summit 2006 were performed at NOAA ESRL. A specific issue for this site is the inconsistency of the $\mathrm{SF}_{6}$ dataset with the other trace-gas data (see Figure 10). At the time of Summit 2006 firn air measurement, the NOAA ESRL analytical system was optimized to measure near ambient $\mathrm{SF}_{6}$ values, and a calibration bias is suspected for lower $\mathrm{SF}_{6}$ concentrations. Buizert et al. (2011) also describes $\mathrm{SF}_{6}$ specific issues at NEEM. We should note that NEEM and Summit are the most recently drilled sites in this study (2008 and 2006), thus an inconsistency of the firn data with the recent $\mathrm{SF}_{6}$ scenario could also contribute to the $\mathrm{SF}_{6}$ upper firn issues at NEEM and Summit. Summit diffusivities were calculated with/without $\mathrm{SF}_{6}$. The most affected species are those with the latest emission start: $\mathrm{CFC}-113$ and HFC-134a. As including SF 6 brings the fit of CFC-113 and HFC-134a outside error bars at some depths without allowing for a good fit of $\mathrm{SF}_{6}$, the diffusivity calculated without $\mathrm{SF}_{6}$ is used as our reference diffusivity. 

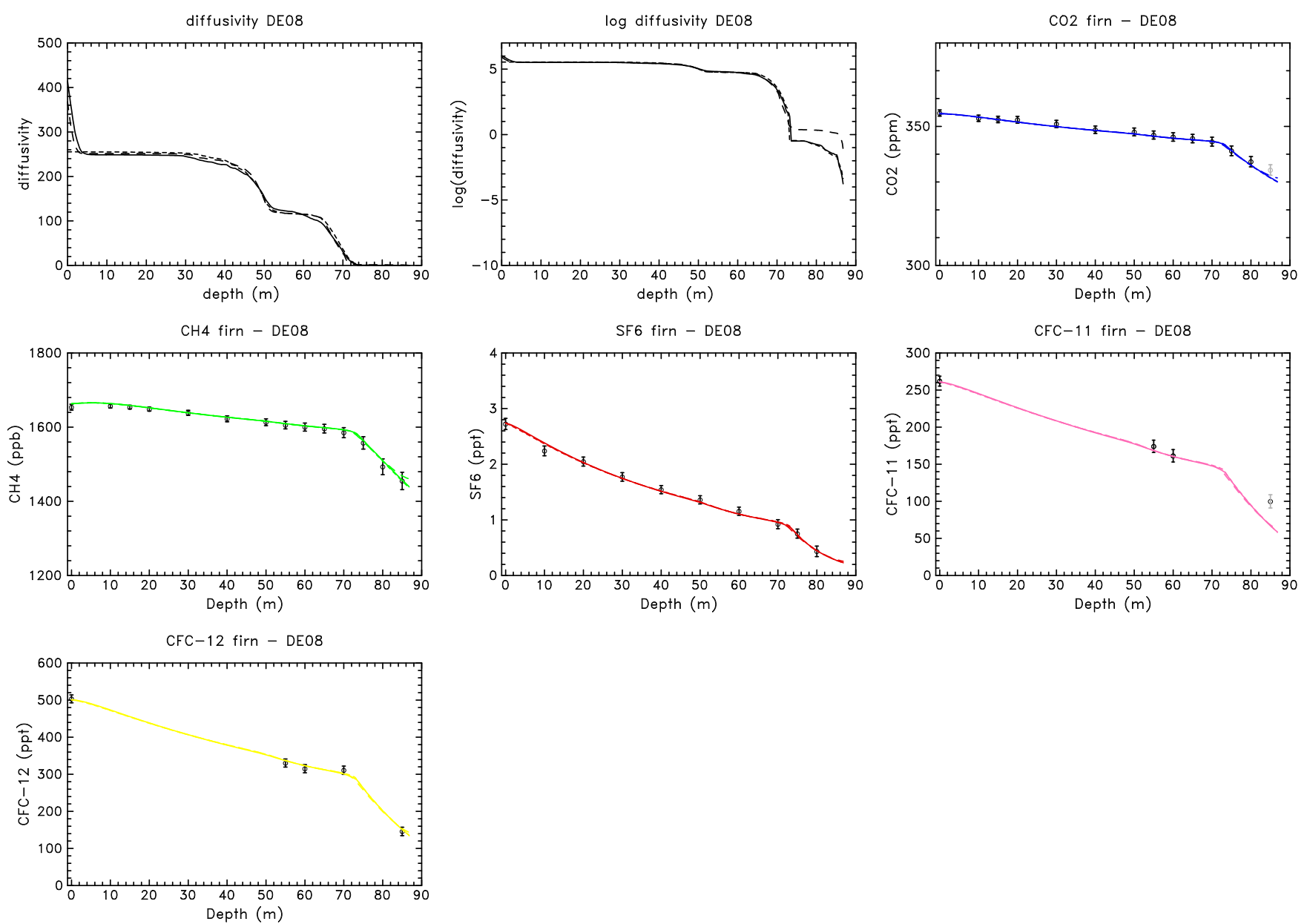

Fig. 8. Diffusivity (in $\mathrm{m}^{2} / \mathrm{year}$ ) and gas concentrations at DE08: parameterized initial diffusivity ('- '), zero initial diffusivity ('- - -’) and using $\mathrm{CO}_{2}$ at the deepest level ('- - ').

\subsection{North GRIP}

North GRIP firn data were introduced in Section 3.3. We should note that the two deepest $\mathrm{CO}_{2}$ data points show a similar anomaly as in the NEEM firn (Buizert et al., 2011). North GRIP presents a unique feature in the near-surface firn (Fig. 11): firn data in the first $\sim 8$ meters deviate from the monthly scenarii for at least three species: $\mathrm{SF}_{6}, \mathrm{CFC}-11$ and CFC-12. This may be interpreted as the fast diffusion in the firn of an atmospheric anomaly. This situation looks like what is expected from in a firn convective zone where very rapid transport would produce an absence of concentration gradient with respect to the atmosphere. However, 465 the modeled surface concentrations cannot deviate from the scenario values at drill date, and the diffusivity calculation produces very variable results in the upper 10 meters. Artificially setting the drill date atmospheric scenario values to the near-surface firn value for $\mathrm{SF}_{6}, \mathrm{CFC}-11$ and $\mathrm{CFC}-470$ 12 leads to a correct simulation of the upper firn results. at a sub-monthly time scale (our atmospheric scenarii have a monthly time step). Most importantly, deeper firn concentrations show very little sensitivity to the near-surface diffusivity.

\subsection{Berkner}

Berkner firn data were introduced in Section 3.3. A specific issue for this site is the fact that data below $58 \mathrm{~m}$ depths are suspected to be contaminated by a leak in the air pumping system (Worton et al., 2007). Using no data below $57 \mathrm{~m}$ depth (Fig. 12) produces a good match of the non-suspect dataset but leads to anomalously narrow age distributions by comparison with other sites. Using the apparently least contaminated data point: $\mathrm{CH}_{4}$ at $63 \mathrm{~m}$ depth leads to Green functions more consistent with other sites without modifying the fit of the other data. The absence of constraint in the deep Berkner firn thus likely leads to an increased uncertainty on the Green function. 

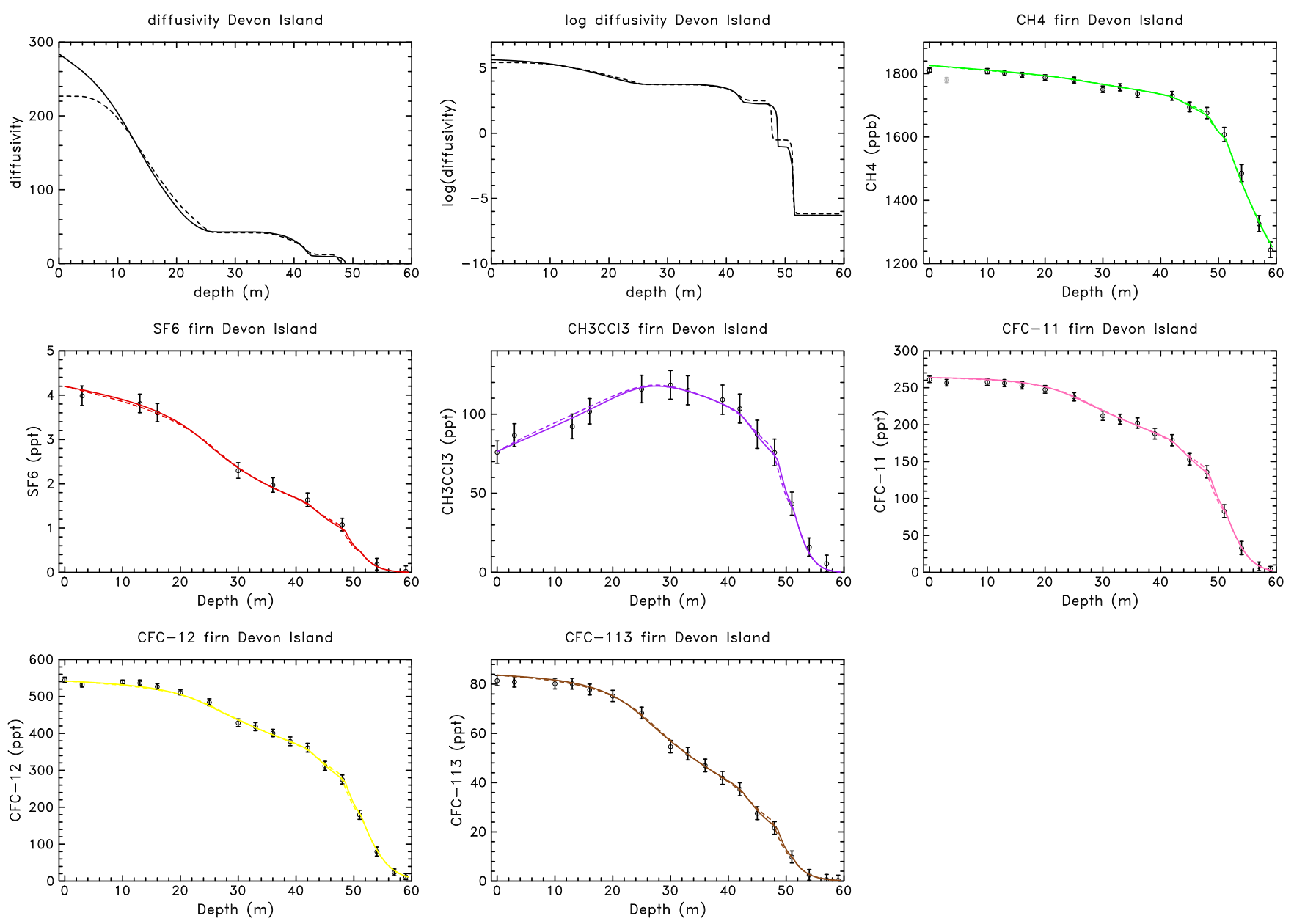

Fig. 9. Diffusivity (in $\mathrm{m}^{2} / \mathrm{year}$ ) and gas concentrations at Devon Island: parameterized initial diffusivity ('-') and zero initial diffusivity ('- -').

\subsection{Siple Dome}

Reference gas measurements for Siple Dome were perall species show a positive concentration anomaly (see Figure 13), thus this depth level was not taken into account in diffusivity calculation. A specific test was performed for the $56.5 \mathrm{~m}$ depth level: halocarbon measurements at very low concentration levels are difficult to perform and can be more sensitive to contamination. In our base case simulations, only the $\mathrm{CO}_{2}$ concentration is considered at this last measurement depth. If concentrations of $\mathrm{SF}_{6}, \mathrm{CFC}-11, \mathrm{CFC}-113500$ and $\mathrm{CH}_{3} \mathrm{CCl}_{3}$ at $56.5 \mathrm{~m}$ depth are also taken into account, the modeled $\mathrm{CO}_{2}$ concentration increases, deviating from the $\mathrm{CO}_{2}$ deepest data point.

\subsection{South Pole}

Two drilling operations performed at South Pole in 1995 (Fig. 14) and 2001 (Fig. 15) were modeled. Reference
490 gas measurements for South Pole were performed at NOAA ESRL (Battle et al., 1996; Butler et al., 1999).

Halocarbon concentrations in the deep South Pole 1995 firn show non-monotonous variations. Data points below the shallowest level showing a higher concentration than the upper depth level were not considered for diffusivity calculation (except for $\mathrm{SF}_{6}$, for which it would have eliminated all data below $70 \mathrm{~m}$ ).

Less reference gas data are available for South Pole 2001. Sampling procedure tests were performed during this drilling operation, which may explain the presence of outlier points also for $\mathrm{CO}_{2}$ and $\mathrm{CH}_{4}$. A direct model test was performed using the South Pole 1995 reference diffusivity while simulating South Pole 2001. The fit of the reference gas data exceeds error bars only around $115 \mathrm{~m}$ depth. We should note that our simulation conditions are more different between South Pole 1995 and South Pole 2001 than between NEEMEU and NEEM-US. In addition to the use of different end dates (drill dates) for the atmospheric scenarii, the South Pole 

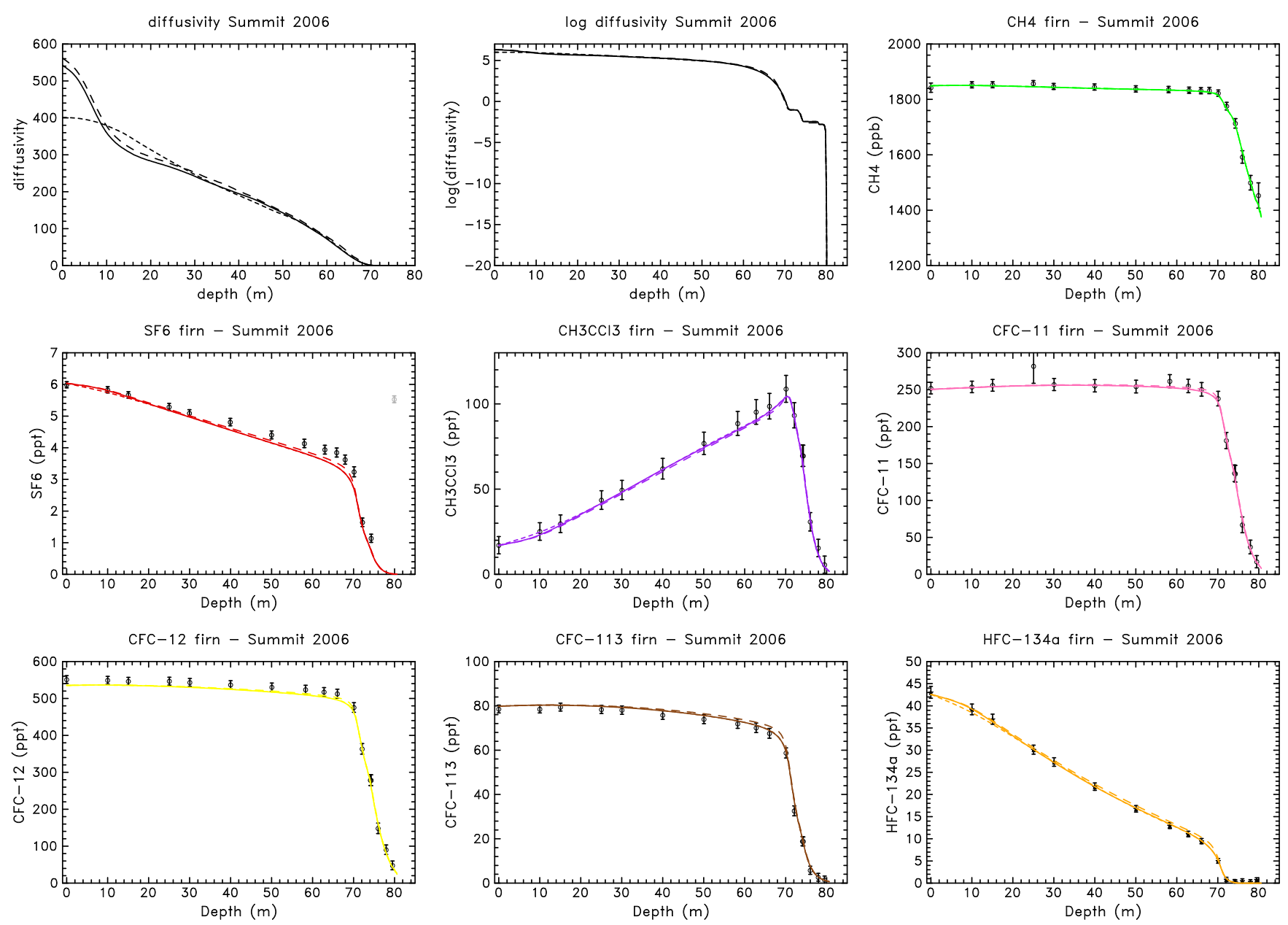

Fig. 10. Diffusivity (in $\mathrm{m}^{2} / \mathrm{year}$ ) and gas concentrations at Summit: parameterized initial diffusivity ('-'), zero initial diffusivity ('- - -') and using $\mathrm{SF}_{6}$ as a reference gas ('---').

simulations use different density profiles (measured for each operation).

\subsection{Dronning Maud Land}

Dronning Maud Land (DML) firn data were introduced in Section 3.3. The $\mathrm{CH}_{4}$ (and to a lesser extent $\mathrm{CO}_{2}$ ) data at this site show unusual wiggles (Fig 16). As a consequence an increased experimental uncertainty (15 ppb instead of $10 \mathrm{ppb})$ was assigned to $\mathrm{CH}_{4}$ at DML. The initial solution test pro- ${ }_{535}$ vides somewhat different solutions in the upper firn, although within error bars. One produces a better fit of $\mathrm{CH}_{3} \mathrm{CCl}_{3}$, and a degraded fit of $\mathrm{SF}_{6}$, the other one does the reverse. The two fits are of nearly equivalent quality (their root mean square deviations from the data (RMSD) differ by less than $1 \%$ ). Thus the DML case illustrates the fact that our inverse algorithm does not always find the absolute minimal solution. 540 However the numerous tests performed at 13 drill sites never tions with significantly different quality.

\subsection{Dome C}

Dome C firn data were introduced in Section 3.3. Dome $\mathrm{C}$ is the site where the RMSD minimized by the inversion algorithm is the highest $(R M S D=0.98)$. The model/data comparison on Figure 17 suggests that the model has difficulty to conciliate the different datasets around 85-90 meters depth. Near surface unfitted points $\left(\mathrm{CO}_{2}\right.$ at $\sim 0 \mathrm{~m}$ and $\sim 10 \mathrm{~m}, \mathrm{CFC}-12$ at $\sim 0 \mathrm{~m}$ ), which might be due to the inability of the model to capture sub-monthly time scale atmospheric variability, have a high weight in the cost function and also degrade the quality indicators of the solution.

\subsection{Vostok}

$\mathrm{CO}_{2}$ and $\mathrm{CH}_{4}$ measurements in the Vostok firn were performed at LGGE (Rommelaere et al., 1997). The two reference gases are very consistent: the model fits both datasets well within error bars (see Figure 18). The ${ }^{15} \mathrm{~N}$ of $\mathrm{N}_{2}$ record at Vostok shows a $13 \mathrm{~m}$ deep convective zone: gravitational 

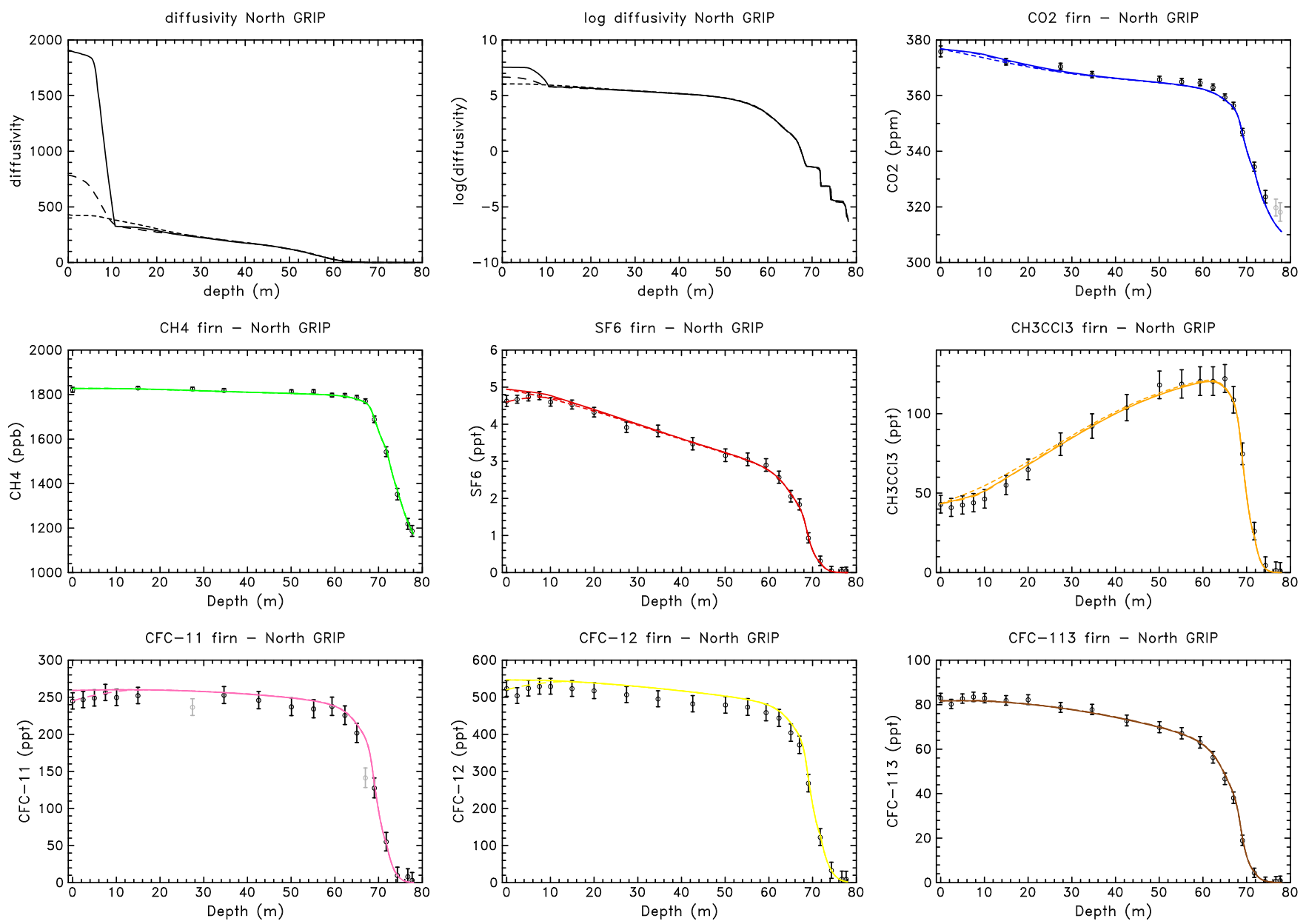

Fig. 11. Diffusivity (in $\mathrm{m}^{2} / \mathrm{year}$ ) and gas concentrations at North GRIP: parameterized initial diffusivity ('-'), zero initial diffusivity ('- -') and changing the final (drill date) atmospheric scenario values for $\mathrm{SF}_{6}, \mathrm{CFC}-11$ and $\mathrm{CFC}-12$ ('- - -').

fractionation of ${ }^{15} \mathrm{~N}$ starts at $13 \mathrm{~m}$ depth (Bender et al., 1994).

The model gravitational fractionation for all gases also starts at $13 \mathrm{~m}$ depth for the reference simulation and the initial solution test. In the second test shown in Figure 18, modeled gravitational fractionation starts at the firn surface. The up- ${ }^{56}$ per firn diffusivity produced is less different from the reference case than the diffusivity from the null initial solution test. However in the initial solution test, higher diffusivities above $20 \mathrm{~m}$ seem compensated by lower diffusivities be- 570 low and produce no visible difference on the modeled trace gas concentrations, and a RMSD close to the reference solution (3.5\% difference). On the other hand, starting gravitational fractionation at the surface leads to a RMSD increase by $35 \%$ ) and modifies somewhat the fit of the $\mathrm{CO}_{2}$ dataset. ${ }^{575}$ In our inverse model context, this does not mean that $\mathrm{CO}_{2}$ is more affected by gravitational fractionation than $\mathrm{CH}_{4}$, but that the model prioritizes the fit of $\mathrm{CH}_{4}$ data, which have smaller error bars (in fact a higher signal to noise ratio) in ${ }_{580}$ the upper firn.

\section{References}

Battle, M., Bender, M., Sowers, T., Tans, P., Butler, J. H., Elkins, J. W., Ellis, J. T., Conway, T., Zhang, N., Lang, P., and Clarke, A.: Atmospheric gas concentrations over the past century measured in air from firn at the South Pole, Nature, 383, 231-235, 1996.

Bender, M. L., Sowers, T., Barnola, J.-M., and Chappellaz, J.: Changes in the $\mathrm{O}_{2} / \mathrm{N}_{2}$ ratio of the atmosphere during recent decades reflected in the composition of air in the firn at Vostok Station, Antarctica, Geophys. Res. Lett., 21, 189-192, 1994.

Buizert, C., Martinerie, P., Petrenko, V., Severinghaus, J., Trudinger, C., Witrant, E., Rosen, J., Orsi, A., Rubino, M., Etheridge, D., Steele, L., Hogan, C., Laube, J., Sturges, W., Levchenko, V., Smith, A., Levin, I., Conway, T., Dlugokencky, E., Lang1, P., Kawamura, K., Jenk, T., White, J., Sowers, T., Schwander, J., and Blunier, T.: Gas transport in firn: multipletracer characterisation and model intercomparison for NEEM, Northern Greenland, Atmos. Chem. Phys. Discussions, 2011.

Butler, J. H., Battle, M., Bender, M. L., Montzka, S. A., Clarke, A. D., Saltzman, E. S., Sucher, C. M., Severinghaus, J. P., and 

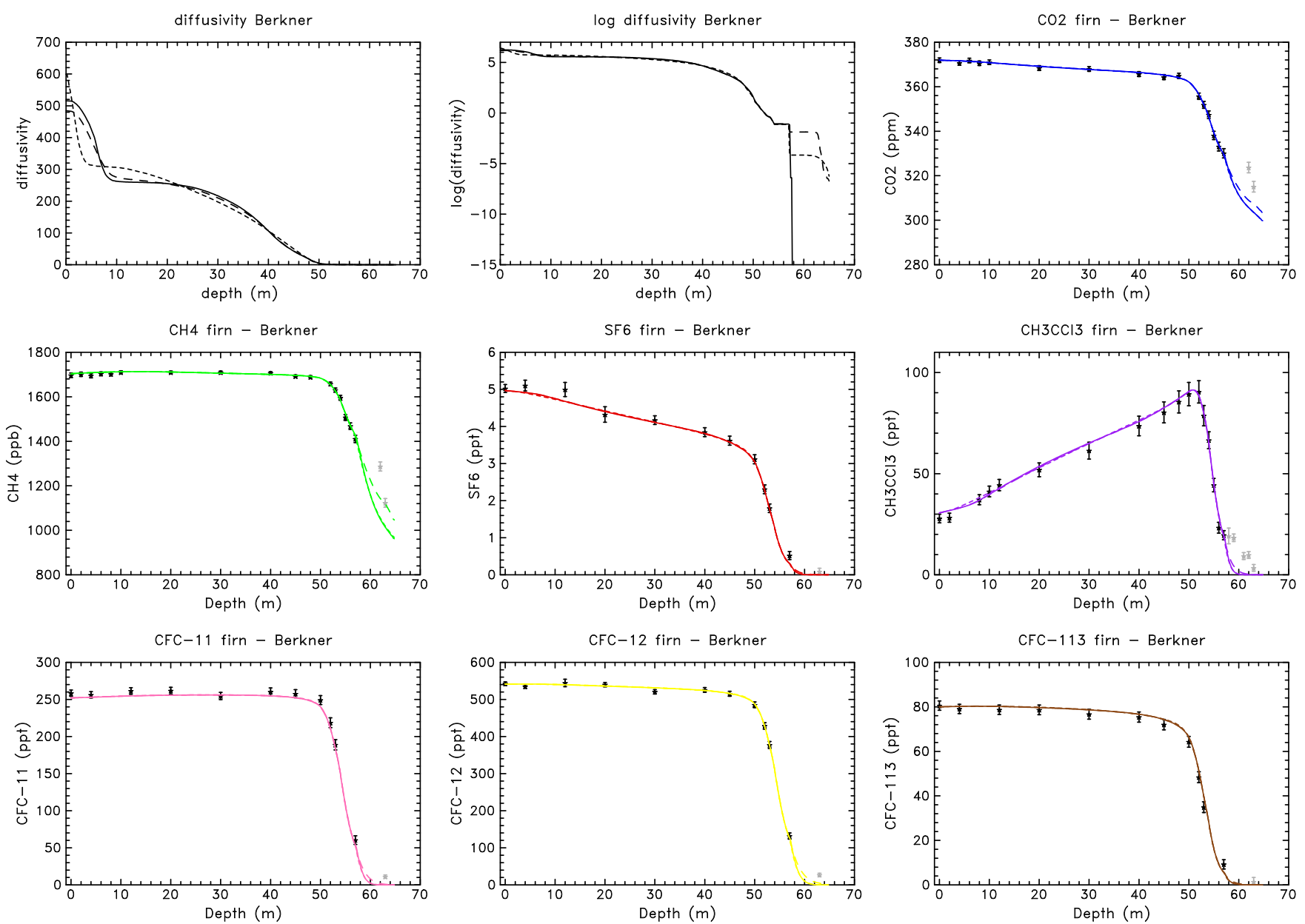

Fig. 12. Diffusivity (in $\mathrm{m}^{2} / \mathrm{year}$ ) and gas concentrations at Berkner: parameterized initial diffusivity ('-'), zero initial diffusivity ('- - -') and using $\mathrm{CH}_{4}$ in the last depth level ('- - ').

Elkins, J. W.: A record of atmospheric halocarbons during the twentieth century from polar firn air, Nature, 399, 749-755, 605 1999.

CRYOSTAT: CRYOspheric STudies of Atmospheric Trends in stratospherically and radiatively important gases (CRYOSTAT), http://badc.nerc.ac.uk/data/cryostat, access: January 2011, 2007.

FIRETRACC: Firn Record of Trace Gases Relevant to Atmospheric 610 Chemical Change over 100 yrs (FIRETRACC/100), http://badc. nerc.ac.uk/data/firetracc, access: January 2011, 2007.

Goujon, C., Barnola, J.-M., and Ritz, C.: Modeling the densification of firn including heat diffusion: application to close-off, Journal of Geophysical Research, 108, ACL10.1-ACL10.18, 2003.

Hirsch, C.: Numerical Computation of Internal and External Flows, vol. 1: The Fundamentals of Computational Fluid Dynamics, Butterworth-Heinemann, $2^{\text {nd }}$ edn., 2007.

Martinerie, P., Nourtier-Mazauric, E., Barnola, J.-M., Sturges, W. T., Worton, D. R., Atlas, E., Gohar, L. K., Shine, 620 K. P., and Brasseur, G. P.: Long-lived halocarbon trends and budgets from atmospheric chemistry modelling constrained with measurements in polar firn, Atmospheric Chemistry and Physics, 9, 3911-3934, doi:10.5194/acp-9-3911-2009, http:// www.atmos-chem-phys.net/9/3911/2009/, 2009.

Mattheij, R., Rienstra, S., and ten Thije Boonkkamp, J.: Partial Differential Equations: Modeling, Analysis, Computation, SIAM, 2005.

Rommelaere, V., Arnaud, L., and Barnola, J.: Reconstructing recent atmospheric trace gas concentrations from polar firn and bubbly ice data by inverse methods, Journal of Geophysical Research, 102, 30 069-30 083, 1997.

Schwander, J.: The Environmental Record in Glaciers and Ice Sheets, chap. The transformation of snow to ice and the occlusion of gases, pp. 53-67, John Wiley, New York, 1989.

Severinghaus, J. and Battle, M.: Fractionation of gases in polar ice during bubble close-off: New constraints from firn air $\mathrm{Ne}, \mathrm{Kr}$ and Xe observations, Earth and Planetary Science Letters, pp. 474-500, 2006.

Severinghaus, J., Sowers, T., Brook, E., Alley, R., and Bender, M.: Timing of abrupt climate change at the end of the Younger Dryas period from thermally fractionated gases in polar ice, Nature, 391, 1998.

Severinghaus, J. P., Albert, M. R., Courville, Z. R., Fahnestock, M. A., Kawamura, K., Montzka, S. A., Mühle, J., Scambos, 

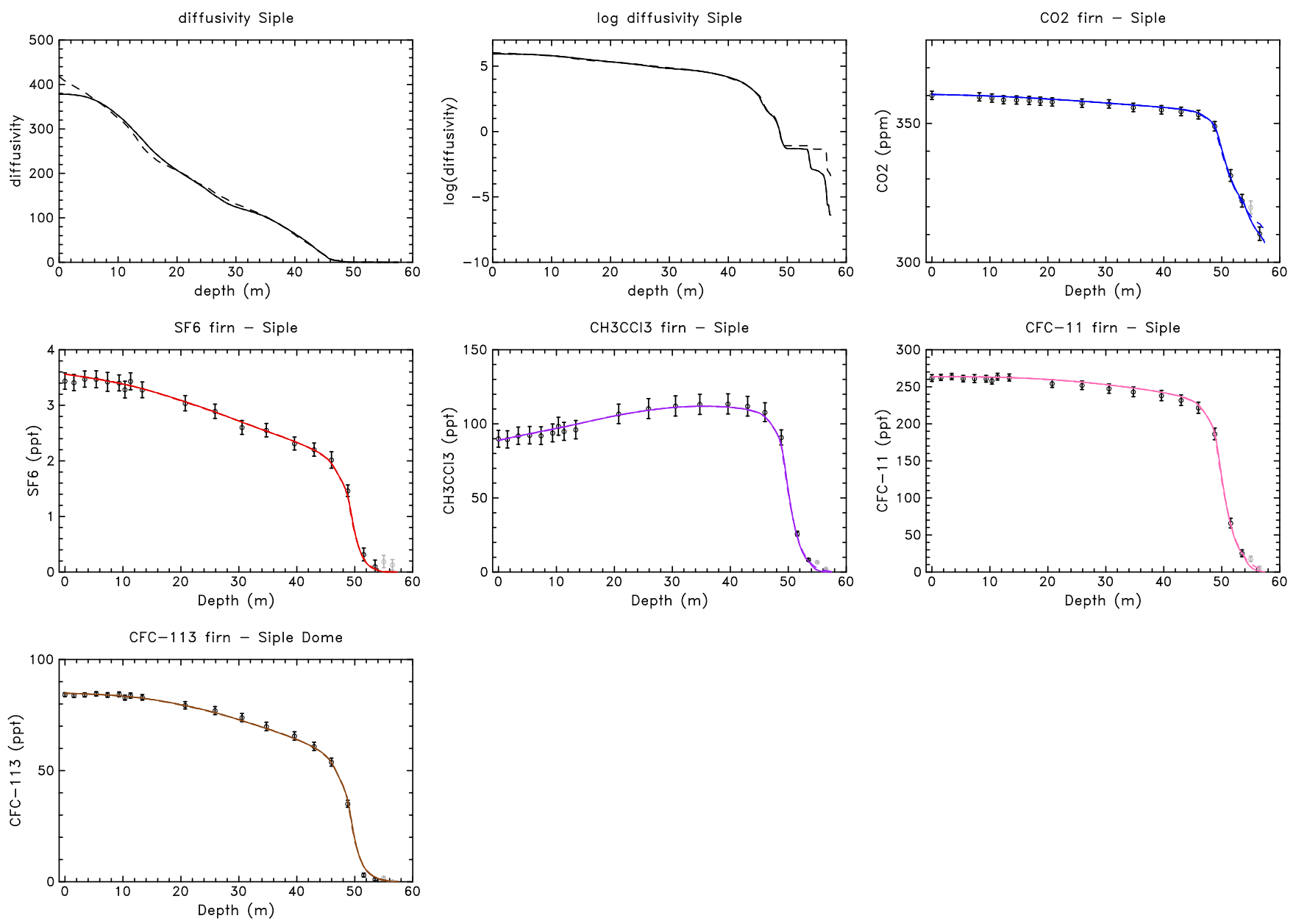

Fig. 13. Diffusivity (in $\mathrm{m}^{2} / \mathrm{year}$ ) and gas concentrations at Siple Dome: parameterized initial diffusivity ('- '), zero initial diffusivity ('- -') and with data points at $56.5 \mathrm{~m}$ depth for SF6, CFC-11, CFC-113 and $\mathrm{CH}_{3} \mathrm{CCl}_{3}$ ('- - -').

T. A., Shields, E., Shuman, C. A., Suwa, M., Tans, P., and Weiss, R. F.: Deep air convection in the firn at a zero-accumulation site, central Antarctica, Earth and Planetary Science Letters, 293, 359-367, 2010.

Trudinger, C., Enting, L., Etheridge, D., Francey, R., Levchenko, V., Steele, L., Raynaud, D., and Arnaud, L.: Modeling air movement and bubble trapping in firn, J. Geophys. Res., 102, 6747-6763, 1997.

Worton, D. R., Sturges, W. T., Gohar, L. K., Shine, K. P., Martinerie, P., Oram, D. E., Humpfrey, S. P., Begley, P., Gunn, L., Barnola, J.-M., Schwander, J., and Mulvaney, R.: Atmospheric Trends and Radiative Forcings of $\mathrm{CF}_{4}$ and $\mathrm{C}_{2} \mathrm{~F}_{6}$ Inferred from Firn Air, Environ. Sci. Technol., 41, 2184-2189, 2007. 

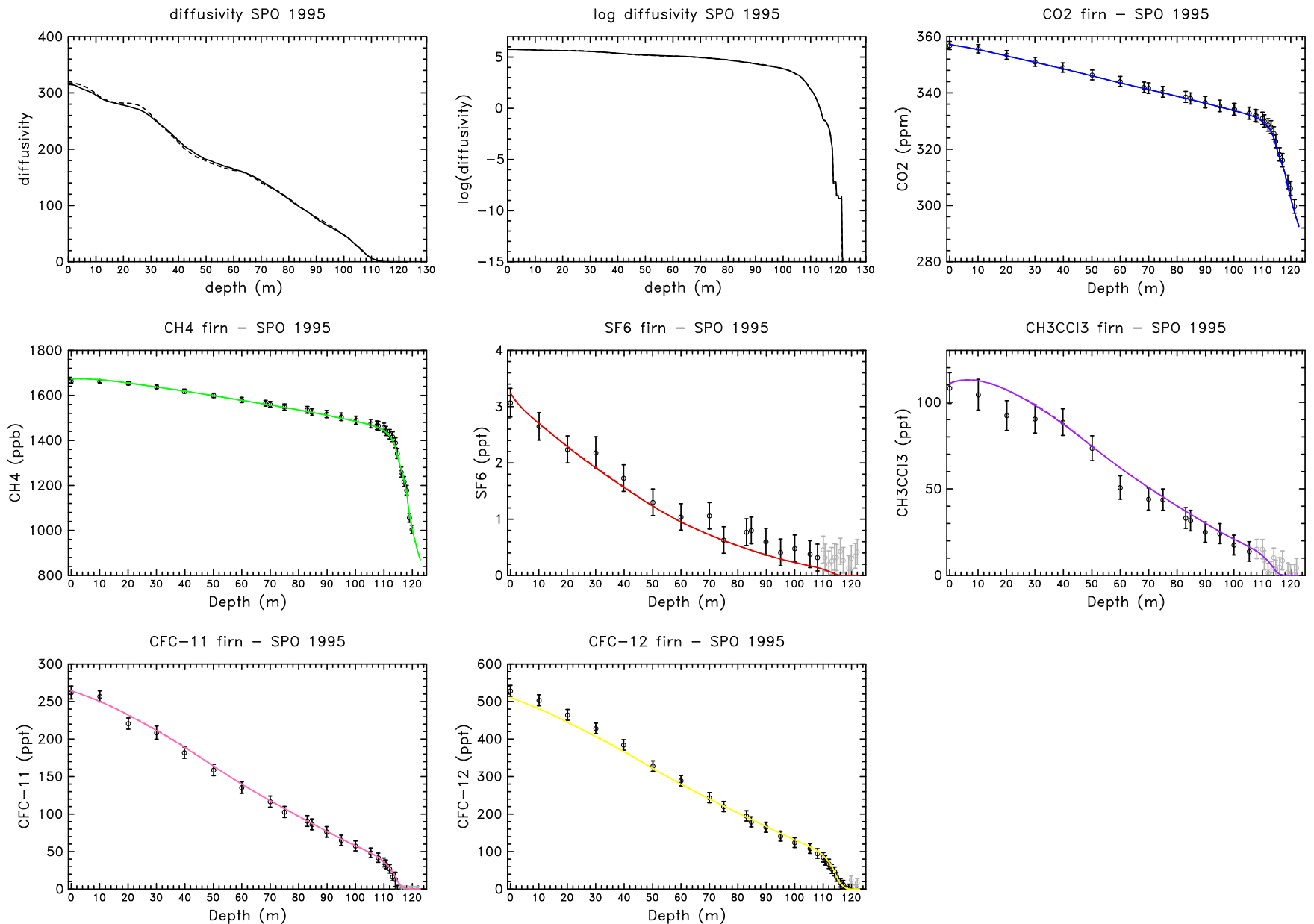

Fig. 14. Diffusivity (in $\mathrm{m}^{2} / \mathrm{year}$ ) and gas concentrations at South Pole in 1995: parameterized initial diffusivity ('-') and zero initial diffusivity ('- - -'). 

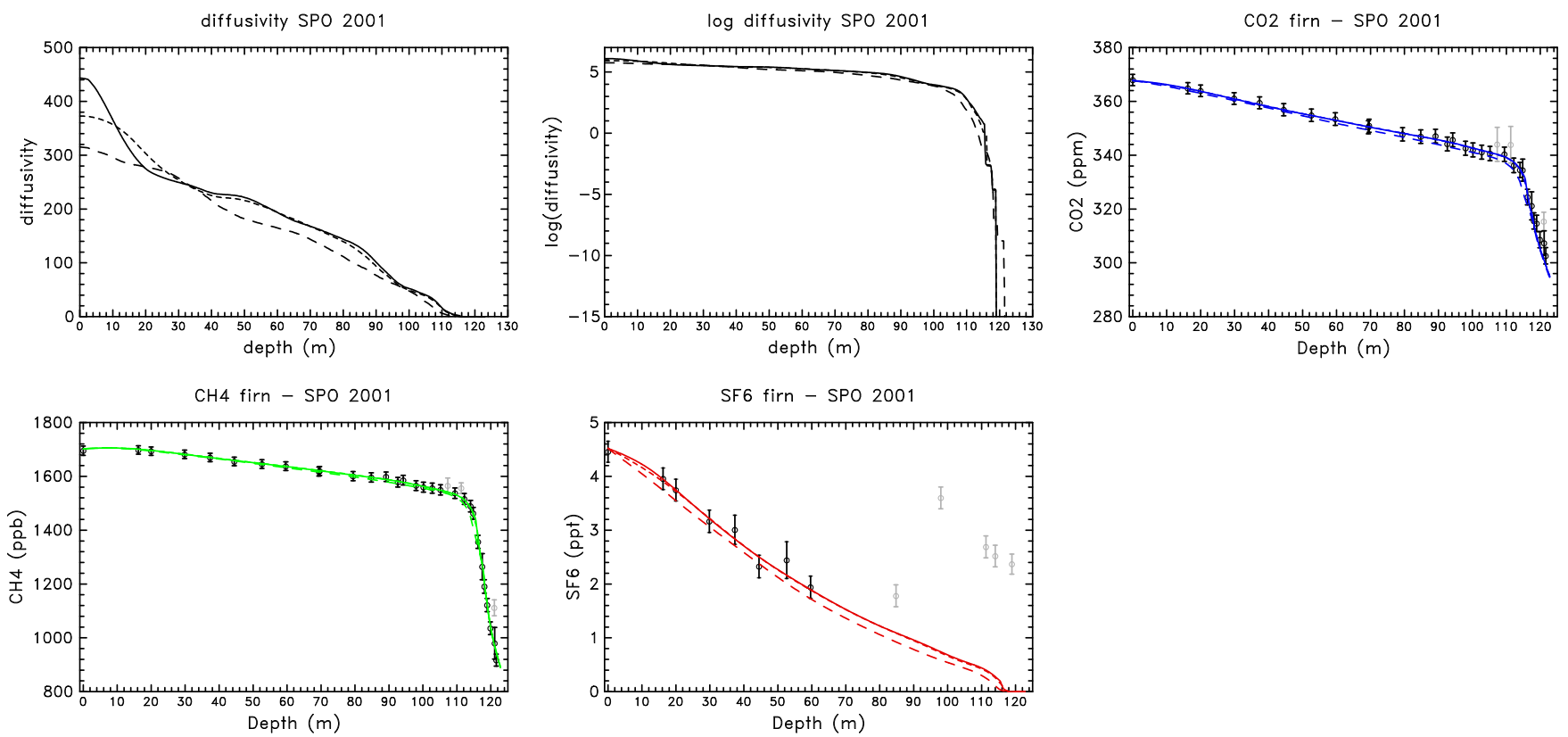

Fig. 15. Diffusivity (in $\mathrm{m}^{2} /$ year) and gas concentrations at South Pole in 2001: parameterized initial diffusivity ('-'), zero initial diffusivity ('- - -') and with the diffusivity obtained from the 1995 measurements ('- - -'). 

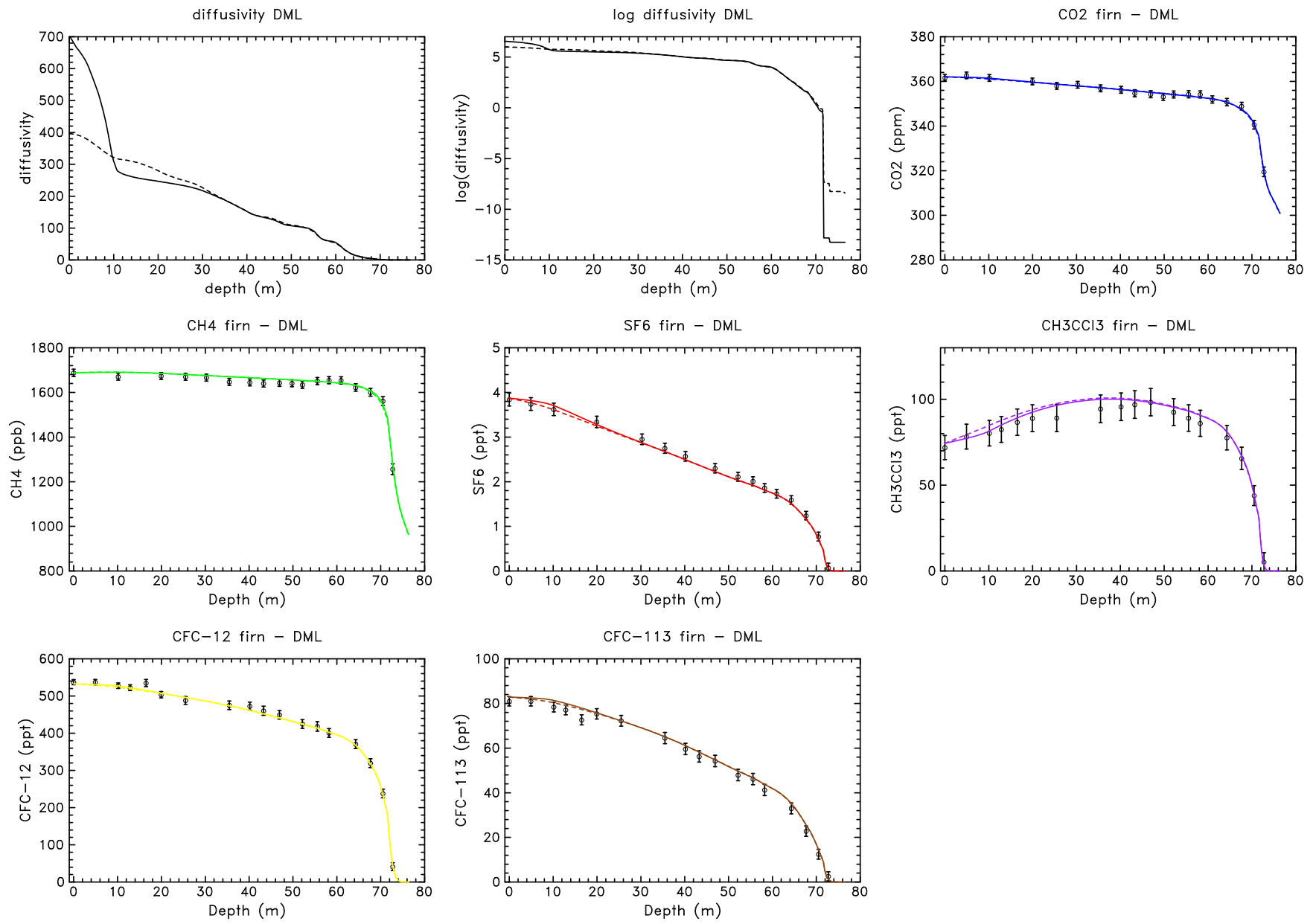

Fig. 16. Diffusivity (in $\mathrm{m}^{2} / \mathrm{year}$ ) and gas concentrations at DML: parameterized initial diffusivity (‘-') and zero initial diffusivity (‘- - -’). 

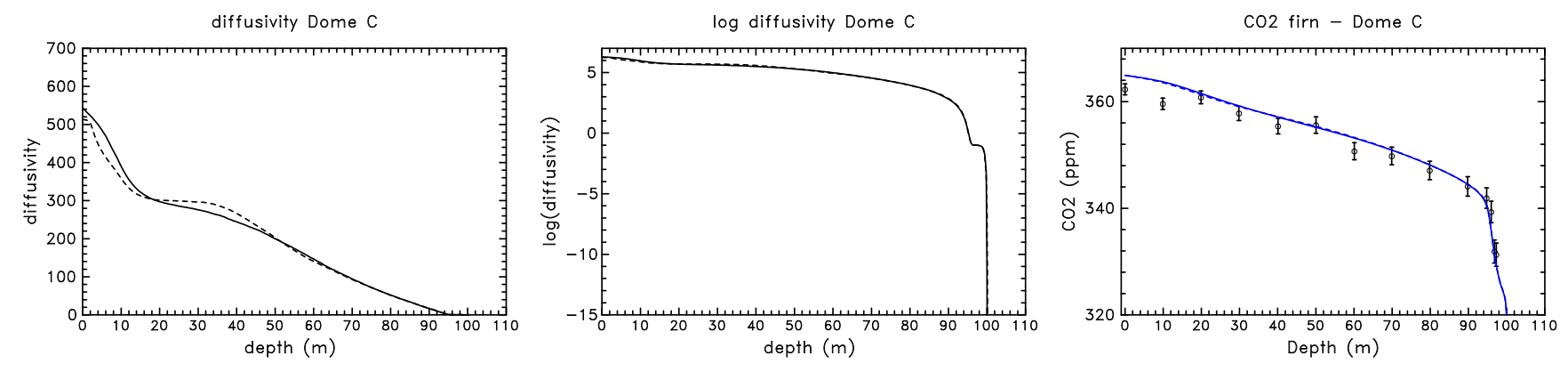

CH4 firn - Dome C
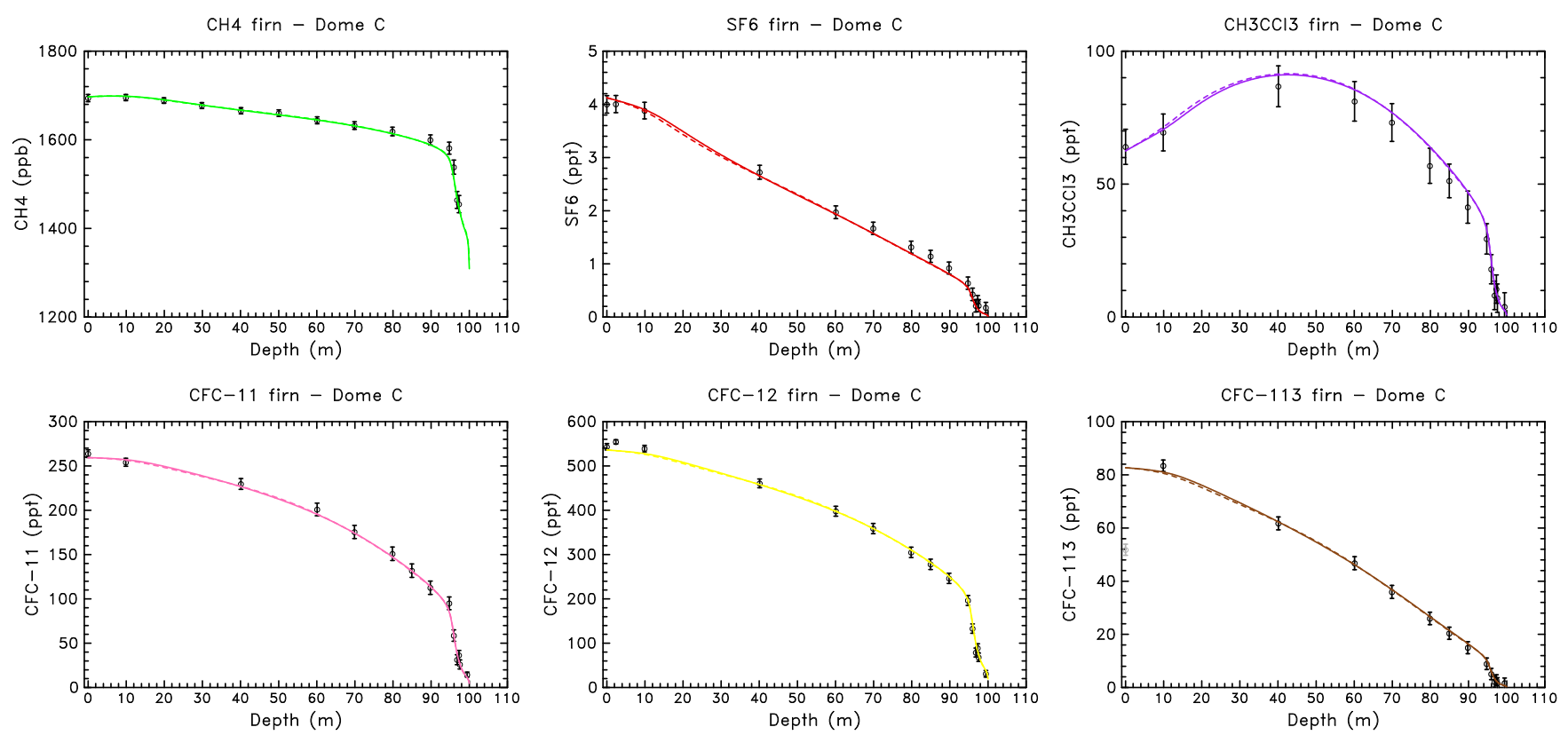

Fig. 17. Diffusivity (in $\mathrm{m}^{2} /$ year) and gas concentrations at Dome C: parameterized initial diffusivity ('-') and zero initial diffusivity ('- -'). 

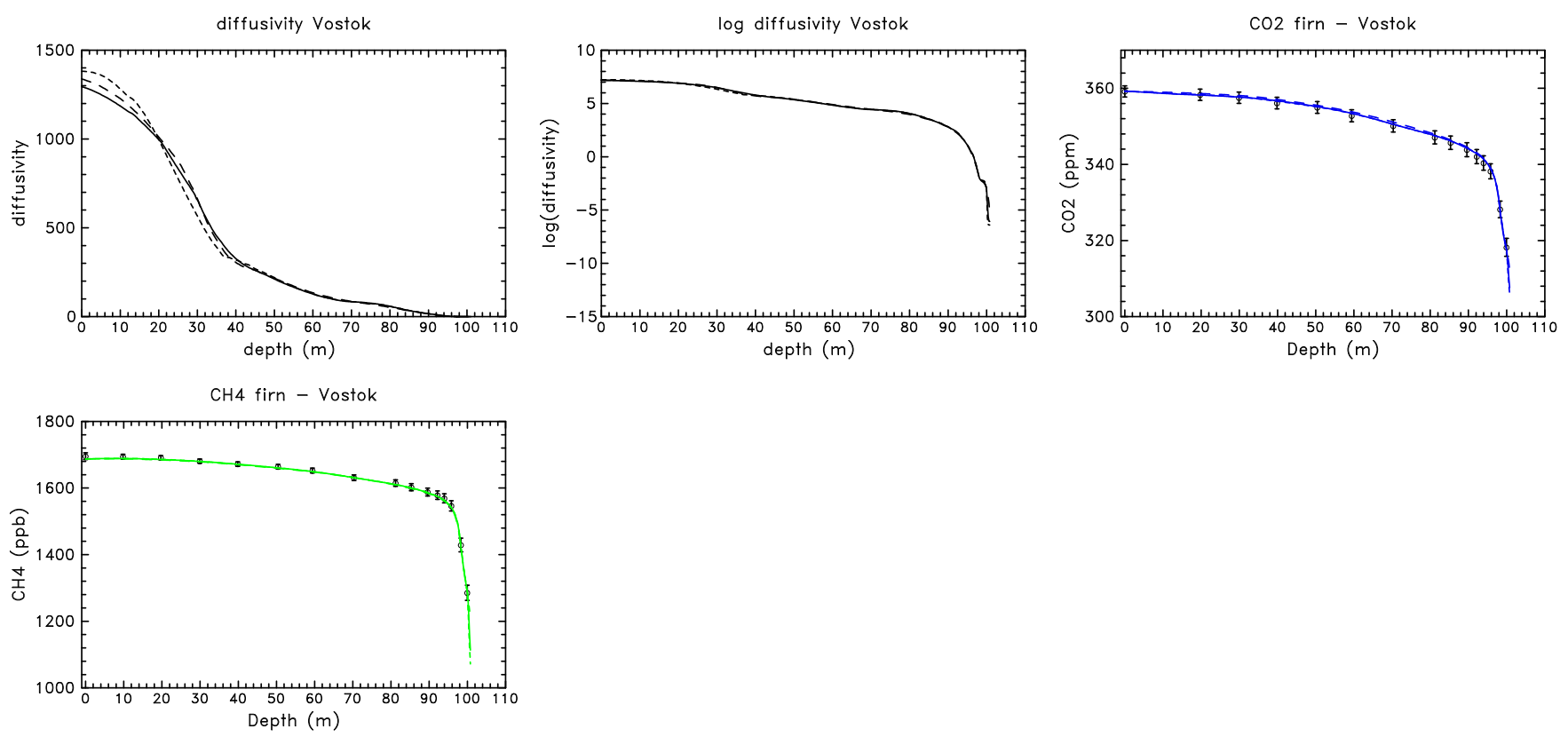

Fig. 18. Diffusivity (in $\mathrm{m}^{2} / \mathrm{year}$ ) and gas concentrations at Vostok: parameterized initial diffusivity ('-—'), zero initial diffusivity ('- - -’) and starting gravitational fractionation at $0 \mathrm{~m}$ rather that $13 \mathrm{~m}\left({ }^{\circ}---'\right)$. 